medRxiv preprint doi: https://doi.org/10.1101/2021.10.11.21264780; this version posted October 14, 2021. The copyright holder for this preprint (which was not certified by peer review) is the author/funder, who has granted medRxiv a license to display the preprint in perpetuity.

It is made available under a CC-BY-NC-ND 4.0 International license .

\title{
Colorectal cancer is associated with the presence of cancer driver mutations in normal colon
}

\section{Running title: Cancer driver mutations in normal colon}

Julia Matas ${ }^{1,2}$, Brendan Kohrn ${ }^{1}$, Jeanne Fredrickson ${ }^{1}$, Kelly Carter ${ }^{3}$, Ming $\mathrm{Yu}^{3}$, Ting Wang ${ }^{3}$, Xianyong Gui ${ }^{1}$, Thierry Soussi ${ }^{4,5,6}$, Victor Moreno ${ }^{7,8,9,10}$, William M. Grady ${ }^{3}$, Miguel A. Peinado ${ }^{2}$, Rosa Ana Risques ${ }^{1 *}$

${ }^{1}$ Department of Laboratory Medicine and Pathology, University of Washington, Seattle, USA

${ }^{2}$ Institut Germans Trias i Pujol, Badalona, Spain,

${ }^{3}$ Fred Hutchinson Cancer Research Center, Seattle, USA

${ }^{4}$ Department of Immunology, Genetics and Pathology, Uppsala University, Uppsala, Sweden

${ }^{5}$ Sorbonne Université, UPMC Univ Paris 06, F- 75005 Paris, France

${ }^{6}$ INSERM, U1138, Centre de Recherche des Cordeliers, Paris, France

${ }^{7}$ Oncology Data Analytics Program, Catalan Institute of Oncology (ICO), Barcelona, Spain

${ }^{8}$ Colorectal Cancer Group, ONCOBELL Program, Institut de Recerca Biomedica de Bellvitge (IDIBELL),

Barcelona, Spain

${ }^{9}$ Consortium for Biomedical Research in Epidemiology and Public Health (CIBERESP), Barcelona, Spain

${ }^{10}$ Department of Clinical Sciences, Faculty of Medicine, University of Barcelona, Barcelona, Spain

*To whom correspondence should be addressed: rrisques@uw.edu

\begin{abstract}
While somatic mutations in colorectal cancer (CRC) are well characterized, little is known about the accumulation of cancer mutations in the normal colon prior to cancer. Here we have developed and applied an ultra-sensitive, single-molecule mutational test based on CRISPR-DS technology, which enables mutation detection at extremely low frequency $(<0.001)$ in normal colon from patients with and without CRC. We found oncogenic KRAS mutations in the normal colon of about one third of patients with CRC but in none of the patients without CRC. Patients with CRC also carried more TP53 mutations than patients without cancer, and these mutations were more pathogenic and formed larger clones, especially in patients with early onset CRC. Most mutations in normal colon were different from the driver mutations in tumors suggesting that the occurrence of independent clones with pathogenic KRAS and TP53 mutations is a common event in the colon of individuals that develop CRC.
\end{abstract}

\section{SIGNIFICANCE}

Our results suggest a prevalent process of somatic mutation and evolution in the normal colon of patients with CRC, which can be detected by ultra-sensitive sequencing of driver genes and potentially employed clinically for CRC risk prediction.

Keywords: somatic mutation, clonal expansions, cancer evolution, early onset colorectal cancer, cancer risk prediction, early cancer detection, precancer, carcinogenic fields, ultra-deep sequencing, duplex sequencing, single molecule sequencing, aging 
medRxiv preprint doi: https://doi.org/10.1101/2021.10.11.21264780; this version posted October 14, 2021. The copyright holder for this preprint (which was not certified by peer review) is the author/funder, who has granted medRxiv a license to display the preprint in perpetuity. It is made available under a CC-BY-NC-ND 4.0 International license .

\section{INTRODUCTION}

Colorectal cancers, like many other solid tumors, form through a process of somatic evolution that takes decades (1). This fact and our current understanding of the molecular pathogenesis of colorectal adenomas and adenocarcinoma imply that clones primed with cancer mutations exist within histologically normal tissue for years prior to cancer diagnosis. Providing convincing evidence of this proposed phenomenon is of critical importance for early cancer detection, risk prediction, and prevention (2,3). However, the robust identification of these mutant clones has been challenging due to the lack of methods able to reliably detect small subsets of mutant cells within morphologically normal tissue.

Two approaches to identify somatic mutations in normal tissue consist of either reducing the sample size to very small or microscopic regions in which mutant clones represent a sizable proportion of cells (4), or of expanding single-cells in vitro to larger clones amenable for nextgeneration sequencing (NGS) (5). These approaches have been applied to the characterization of somatic mutations in normal tissues including skin $(6,7)$, esophagus $(8,9)$, endometrium $(10,11)$, bladder $(12,13)$, colon $(14,15)$, and others $(16,17)$. Many of these studies have revealed an unexpected abundance of cancer driver mutations in histologically normal tissue $(18,19)$ and are rapidly expanding our understanding of the role of somatic evolution in human aging $(20,21)$. However, little is known about how this process differs in individuals with and without cancer, and whether this knowledge can be harnessed to improve cancer prediction and prevention. A main challenge relies on the fact that these approaches require the analysis of a large number of samples per individual and are very labor-intensive, precluding large cohort studies and translational applications.

An alternative approach to detect low frequency somatic mutations within normal tissue consists of performing ultra-deep sequencing using high-accuracy NGS methods such as duplex sequencing (DS) (22). DS employs double-stranded molecular tags, which enable error correction by consensus sequence independently in each DNA strand, effectively decreasing the error rate of sequencing from $10^{-3}$ to $<10^{-7}(23)$. Because each duplex read corresponds to an original DNA molecule, this method enables the detection of single mutant DNA molecules among thousands of non-mutant genomes, thus providing extreme resolution to identify mutant cells in normal tissue by analyzing a single biopsy. The trade-off for this high-throughput, high-sensitive approach for mutation detection is that it requires large sequencing capabilities and therefore is mostly suitable for small target regions. We have used DS to perform ultra-deep sequencing of TP53 in normal gynecological tissues across the human lifespan, revealing a progressive enrichment of TP53 pathogenic mutations with older age (24). We have also demonstrated the presence of cancer driver TP53 mutations in the peritoneal fluid (25), uterine lavage (24) and Pap test DNA (26) of women with and without ovarian cancer. Women with cancer tended to have higher TP53 mutation burden $(25,26)$, suggesting increased TP53 somatic evolution in association with cancer progression.

Colorectal cancer is the second most common cause of cancer death in the USA and its incidence has been increasing in individuals under 50 years of age (27). The need for better biomarkers for 
medRxiv preprint doi: https://doi.org/10.1101/2021.10.11.21264780; this version posted October 14, 2021. The copyright holder for this preprint (which was not certified by peer review) is the author/funder, who has granted medRxiv a license to display the preprint in perpetuity. It is made available under a CC-BY-NC-ND 4.0 International license .

CRC prediction, coupled with easy access to normal tissue via colonoscopy, makes this cancer type especially suitable to study the potential of clonal expansion detection in histologically normal tissue to identify early cancer progression. Our goal was to investigate whether mutations in common CRC genes (TP53, KRAS, PIK3CA and BRAF) could be detected by ultra-deep sequencing $(>1,000 x)$ in single, histologically normal colon biopsies and to determine whether they were more frequent in individuals with CRC than in those who are cancer-free. These genes were selected because, together with $A P C$, they constitute the 5 most frequently mutated genes in CRC. However, in contrast to $A P C$, they accumulate mutations in localized hotspot regions, thus providing excellent targets for the development of ultra-sensitive sequencing tests for early cancer detection. We used a version of DS called CRISPR-DS (28), which employs CRISPR-based target enrichment to increase library preparation efficiency for small target panels. We demonstrate the feasibility of our approach to detect low frequency cancer driver mutations in normal colon, and the potential clinical value of these mutations as CRC risk markers. Our results suggest that this approach could be useful for CRC risk prediction in younger patients, who constitute a rapidly increasing subset of the population at risk (29).

\section{RESULTS}

\section{CRISPR-DS enables ultra-sensitive detection of mutations in normal colon and CRC cell lines}

We used CRISPR-DS to perform ultra-deep sequencing (minimum 1,000x, mean 2,500x) of DNA from the normal colonic epithelium of 47 individuals: 24 without $C R C$ and 23 with CRC (Fig. $1 \mathrm{~A}$ and Methods). Half of the patients with CRC were 50 years of age or younger to allow investigation of the role of somatic mutation load in individuals with early age of onset of CRC. The clinico-pathological characteristics of the individuals are detailed in Supplementary Table S1. We analyzed normal left colon epithelium in individuals without CRC and normal epithelium distant from tumor ( $>10 \mathrm{~cm}$ in most cases) in individuals with CRC.

CRISPR-DS enables ultra-accurate deep-sequencing of selected genomic regions, which are excised with CRISPR-Cas9 in fragments of predetermined size. These fragments are then sizeselected for target enrichment prior to library preparation (28). This process eliminates problems associated with DNA sonication (30) and increases sequencing efficiency (28). We adapted this method to digest in $\sim 260 \mathrm{bp}$ fragments the exons that carry common oncogenic mutations in BRAF, KRAS and PIK3CA and the full coding region of TP53 (Fig. 1B and Methods). The CRISPR RNA (crRNA) sequences for CRISPR-Cas9 digestion and the probes for hybridization capture are indicated in Supplementary Tables S2 and S3, respectively. Duplex adapters containing 8bp random molecular tags were used to uniquely label each DNA molecule to enable double-strand error correction as previously described $(22,28)$ (Fig. 1B, Methods).

We first demonstrated the reproducibility and sensitivity of the assay by deep sequencing DNA from 3 common CRC cell lines with driver mutations in our target genes (HCT116, SW480 and HT29) (Supplementary Methods). All the expected driver mutations were identified in addition to multiple low frequency $(<0.1)$ mutations in HCT116 and several low frequency mutations in 
SW480, in agreement with the known levels of single nucleotide variants in these cell lines (31) (Supplementary Fig. S1A). An independent technical replicate experiment identified not only the expected driver mutations but also all the expected mutations with Mutant Allele Frequency (MAF) as low as 0.001 and a subset of the very rare mutations below 0.001 , despite the decreased likelihood of resampling of a rare event (Supplementary Fig. S1A). These results demonstrate the high sensitivity and reproducibility of the assay even at 0.001 MAF. To further demonstrate sensitivity and accuracy in an independent experiment, we spiked DNA from HT29 into DNA from HCT116 at 3 different ratios (1:10, 1:20, 1:100). The two driver HT29 mutations were observed at the expected frequencies in the 3 mixes even when present at low level (0.01 and 0.003) (Supplementary Fig. S1B).

A

Normal colon tissue collection

\begin{tabular}{|c|}
\hline Individuals \\
without CRC \\
$(\mathrm{n}=24)$ \\
\hline mean age: \\
59 yo (40-79) \\
\hline
\end{tabular}

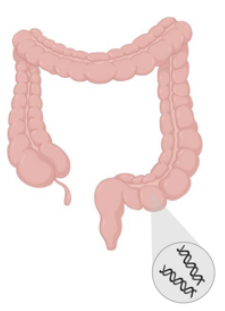

C
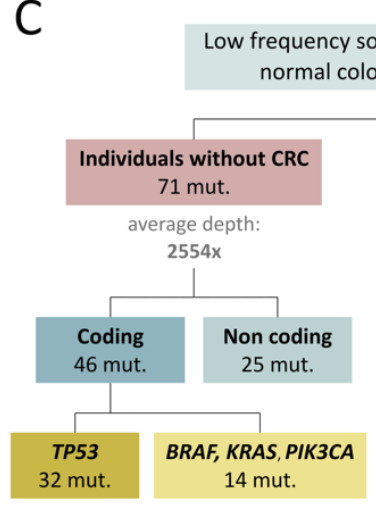
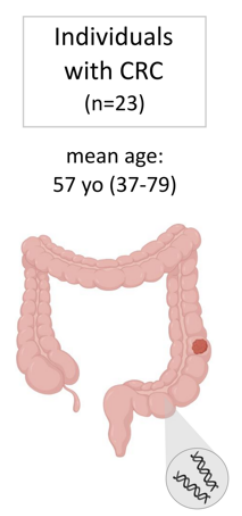

matic mutations in (MAF<0.02)

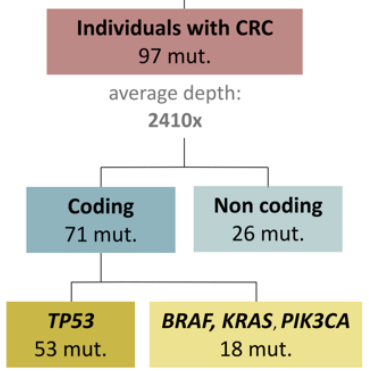

B CRISPR-DS
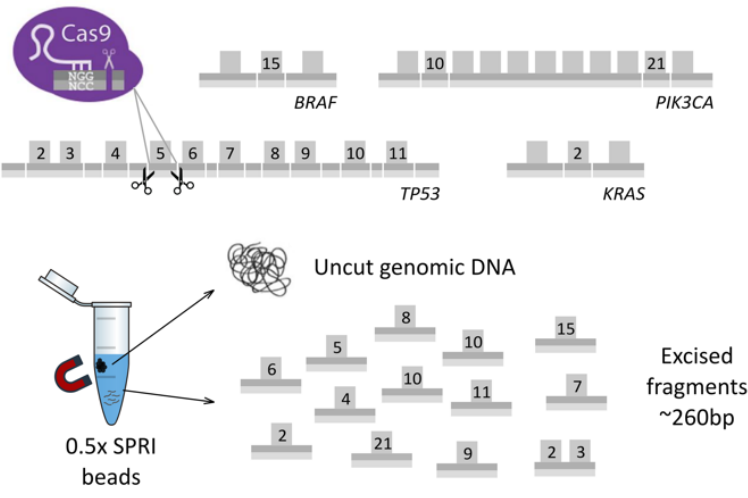

iii

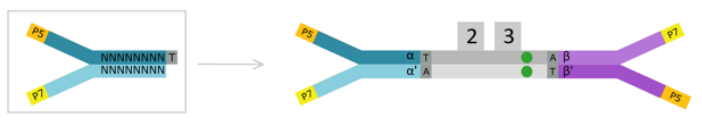

iv

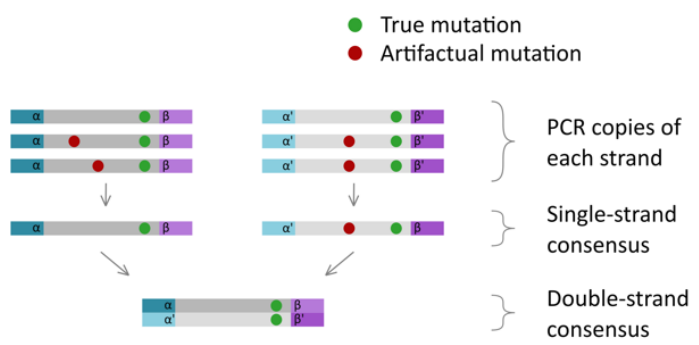

Figure 1. CRISPR-DS enables ultra-sensitive detection of cancer gene mutations in normal colon samples. A. Normal colon biopsies were procured from individuals with and without CRC. B. CRISPR-DS. (i) CRISPR-Cas9 guides were designed to target common oncogenic mutation regions in BRAF, PIK3CA and KRAS as well as the full coding region of TP53 in fragments of $\sim 260 \mathrm{bp}$. (ii) Size selection with SPRI beads was used to enrich for excised fragments. (iii) Excised fragments were ligated to adapters with random double-stranded molecular tags. (iv) The generation of single-strand and double-strand consensus sequences from reads sharing the same molecular tags enables the elimination of artifactual mutations. Adapted from Nachmanson et al (ref. 28). C. Low frequency somatic mutations in cancer genes are identified in normal colon from patients with and without CRC. 
medRxiv preprint doi: https://doi.org/10.1101/2021.10.11.21264780; this version posted October 14, 2021. The copyright holder for this preprint (which was not certified by peer review) is the author/funder, who has granted medRxiv a license to display the preprint in perpetuity. It is made available under a CC-BY-NC-ND 4.0 International license .

We then used CRISPR-DS to sequence the normal colon of individuals with and without CRC. While the mean duplex depth across samples was variable, all samples reached a minimum of 1,000x duplex depth and the average depth for both groups of patients was similar (Fig. 1C). Overall, CRISPR-DS yielded a total of 404M duplex nucleotides, with $227 \mathrm{M}$ in coding regions and $177 \mathrm{M}$ in non-coding regions. A total of 168 mutations were identified: 117 coding and 51 noncoding (Fig. 1C). All these mutations had low MAF (<0.02). As in prior studies (24-26), the number of mutations tended to increase with the number of duplex nucleotides sequenced (Supplementary Fig. S2). To correct for this effect, sample comparisons were made based on mutation frequencies, which were calculated as the number of mutations in a given region (e.g., coding exons) divided by the total number of duplex nucleotides sequenced in that region (Methods). Mutation counts and corresponding mutation frequencies for each sample are shown in Supplementary Table S4.

\section{Individuals with CRC carry a higher frequency of coding mutations than individuals without cancer in a non-age dependent manner}

We first compared coding and non-coding mutation frequencies in the normal colon of patients with and without CRC. Patients with CRC had a significantly higher coding mutation frequency in normal colon than patients without cancer ( $t$-test $p=0.005$, Fig. $2 \mathrm{~A}$ ) even when separating the patients by early and late stage CRC (Supplementary Fig. S3). Non-coding mutation frequency, however, was similar in patients with and without CRC (Fig. 2A). Interestingly, the non-coding mutation frequency significantly increased with age (Spearman's correlation $p=0.024$ ), but this trend was not observed for the coding mutation frequency (Fig. 2B). In addition, higher noncoding mutation frequency correlated with advanced epigenetic age in the normal colon as measured by the Horvath clock, the PhenoAge clock, and the EpiTOC clock, which are wellestablished measurements of epigenetic aging $(32,33)$ (Fig. 2C). Coding mutations did not associate with lower or higher epigenetic age determined by these clocks. These results indicate that while intronic, non-functional mutations accumulate with chronological and biological aging in the normal colon, coding mutations in target driver genes exceed the age-related background level, especially in patients that develop CRC.

To further explore the nature of the coding mutations present in the normal colon of patients with and without cancer, we classified them by mutational spectrum $(C>A, C>G, C>T, T>A, T>C$, $T>G$ ). While all types of mutations were more frequent in patients with cancer, two types were significantly overrepresented: $C>A$ (t-test $p=0.007$ ) and $T>A$ (t-test $p=0.015)$ (Fig. 2D). These two types of mutations are also enriched in CRC based on the Catalogue of Somatic Mutations in Cancer (COSMIC) database (34) (Fig. 2E). These results indicate that the normal colon in individuals with CRC not only carries more coding mutations, but these mutations are more similar to those found in tumors. 
A
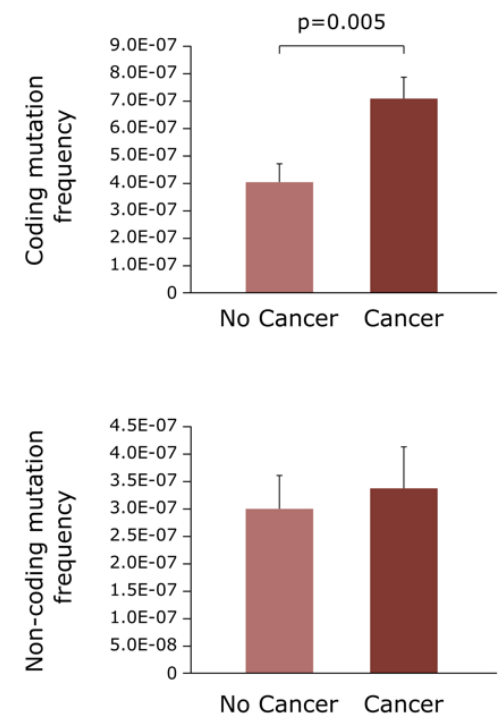

B
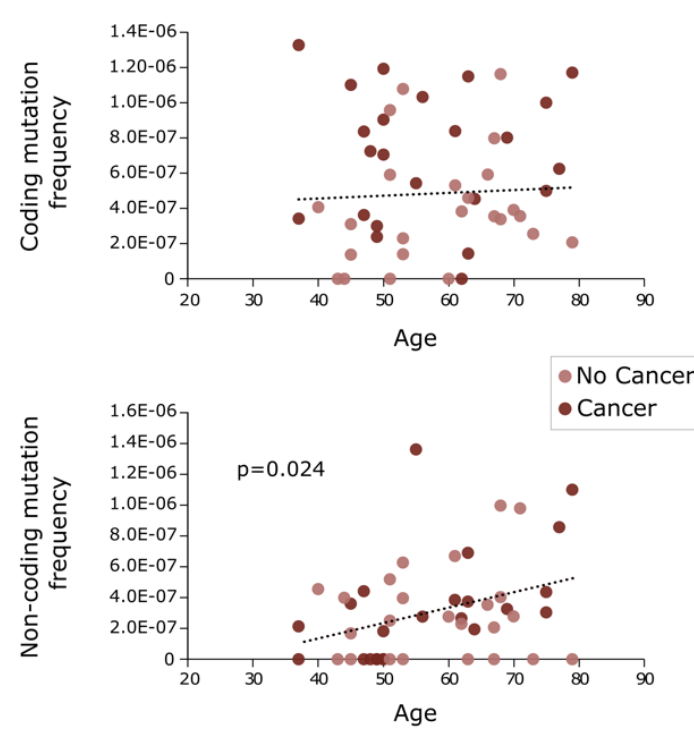

$\mathrm{C}$
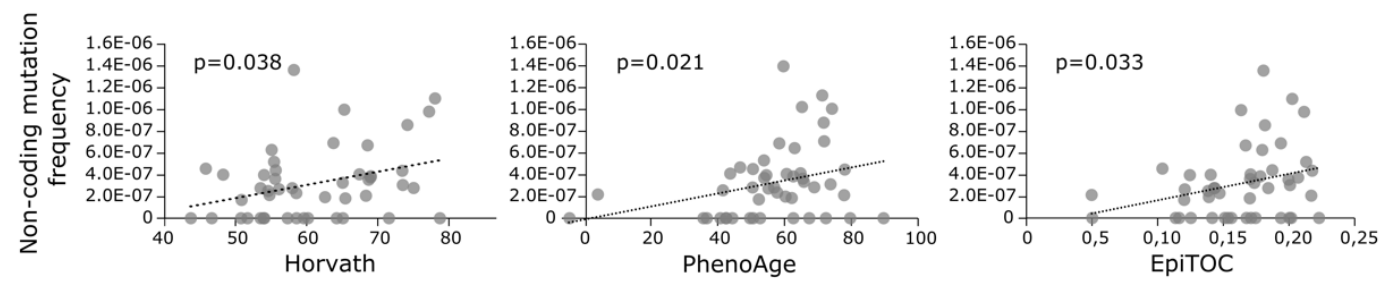

E
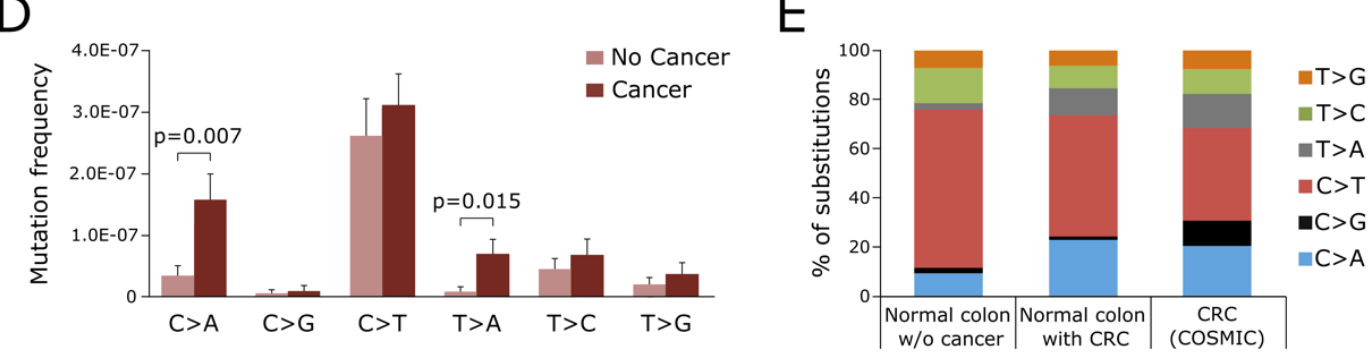

Figure 2. Normal colon of patients with CRC has higher, not age-related, coding mutation frequency and a mutation spectrum similar to cancers. A. Coding and non-coding mutation frequency in normal colon from individuals with and without cancer. Mutation frequency is calculated as the number of mutations divided by the total number of duplex nucleotides sequenced in the coding or non-coding target regions, respectively. P-value corresponds to t-test. Error bars represent standard error of the mean. B. Coding and non-coding mutation frequency and its correlation with age. P-value corresponds to Spearman's correlation. C. Non-coding mutation frequency correlation with Horvath, PhenoAge and EpiTOC epigenetic clocks. P-values correspond to Spearman's correlation. D. Frequency of coding mutation by substitution type compared between normal colon of individuals with and without cancer. P-values correspond to t-tests. Error bars represent standard error of the mean. E. Mutation spectrum compared between coding nucleotide substitutions from normal colon of individuals without CRC ( $n=42)$, with CRC $(n=65)$, and the CRC COSMIC database $(n=70,525)$. Only significant $p$-values are displayed.

\section{KRAS and TP53 driver mutations are abundant in the colon of patients with CRC}

We then explored the distribution of coding mutations by gene (Fig. 3A-C). For BRAF, PIK3CA and $K R A S$, we deep sequenced the exons with CRC mutation hotspots according to the COSMIC 
medRxiv preprint doi: https://doi.org/10.1101/2021.10.11.21264780; this version posted October 14, 2021. The copyright holder for this preprint (which was not certified by peer review) is the author/funder, who has granted medRxiv a license to display the preprint in perpetuity.

It is made available under a CC-BY-NC-ND 4.0 International license .

database. We found several mutations in $B R A F$ and PIK3CA, but none of the BRAF mutations (0/7) corresponded to the canonical hotspot V600E mutation and only two of the PIK3CA mutations (2/12) corresponded to the 3 most common PIK3CA mutations in CRC, which account

A PIK3CA

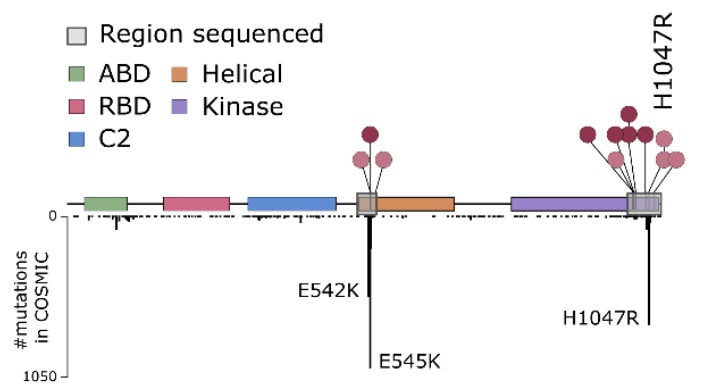

C KRAS

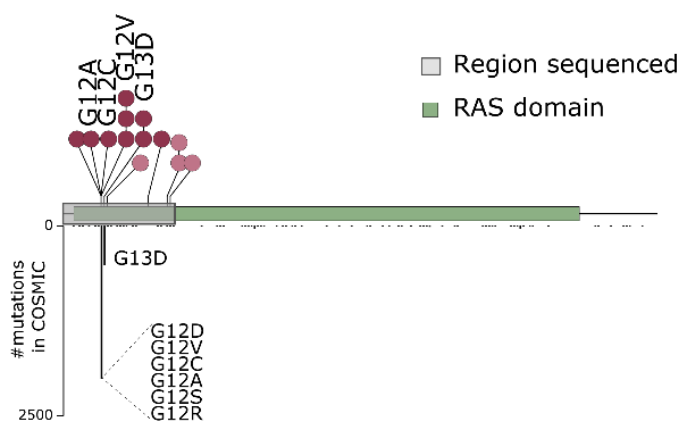

\section{B BRAF}

$\square$ Region sequenced

- RBD $\square$ PKinase

$\square \mathrm{C} 1$

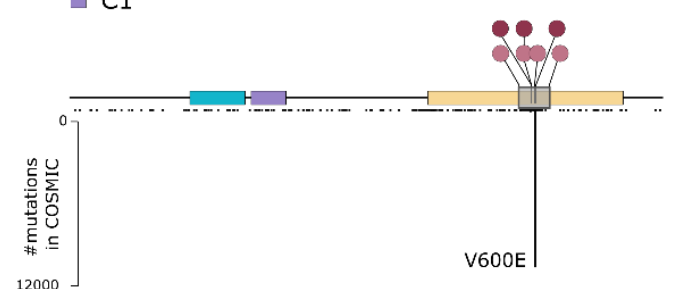

D

KRAS hotspot

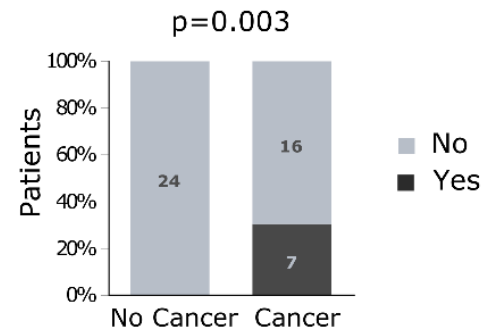

\section{E TP53}

$$
\square \text { TAD1 } \square \text { TAD2 } \square \text { DBD } \square \text { Tetramer }
$$

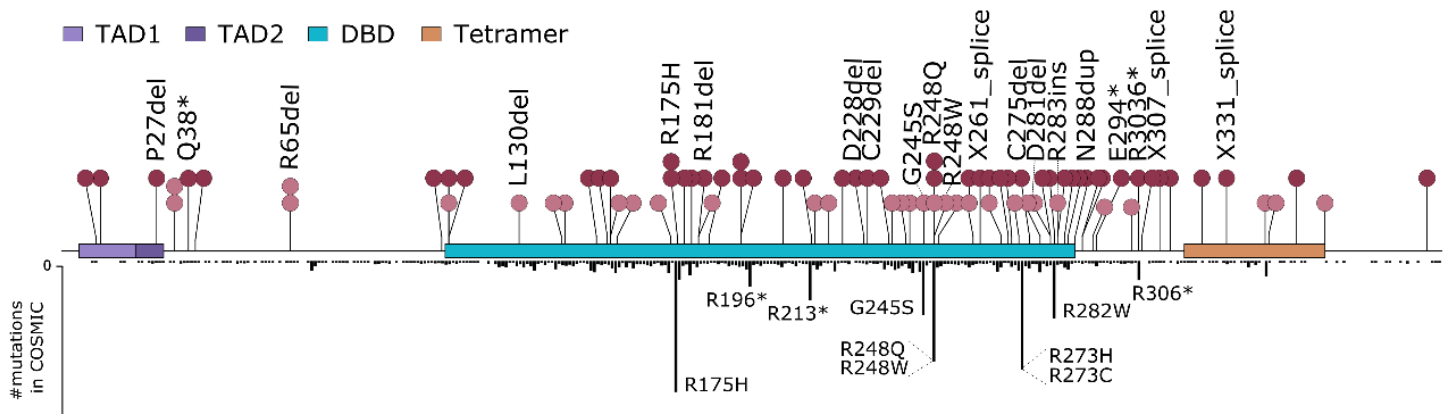

F TP53 coding mutations

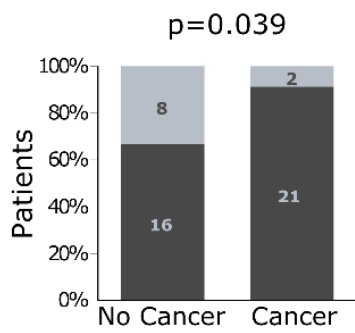

TP53 driver mutations

$p=0.05$

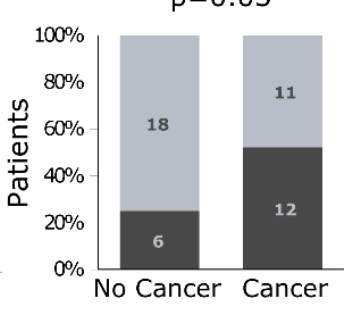

$G$ Overall (KRAS, PIK3CA and TP53) driver mutations

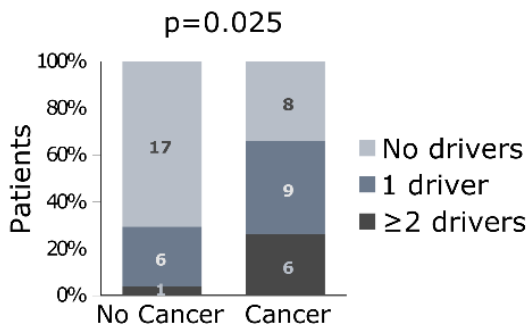


medRxiv preprint doi: https://doi.org/10.1101/2021.10.11.21264780; this version posted October 14, 2021. The copyright holder for this preprint (which was not certified by peer review) is the author/funder, who has granted medRxiv a license to display the preprint in perpetuity. It is made available under a CC-BY-NC-ND 4.0 International license .

Figure 3. Normal colon carries mutations in common CRC genes, but these mutations are more abundant and pathogenic in patients with CRC. A-C. Distribution of mutations in PIK3CA, BRAF and KRAS in normal colon (above gene diagram) and in CRC samples from COSMIC database (below gene diagram). Normal colon mutations are colorcoded by individuals with or without CRC and mutations corresponding to cancer hotspots are indicated. D. Percentage of patients with and without CRC that carry KRAS hotspot mutations in normal colon. E. Distribution of mutations across TP53 in normal colon (above gene diagram) and in CRC samples from COSMIC database (below gene diagram). F. Percentage of patients with and without CRC that carry TP53 coding mutations and driver mutations in their normal colon. G. Percentage of patients with and without CRC that carry one or more different cancer driver mutations in PIK3CA, KRAS, or TP53 their normal colon. P-values correspond to Pearson Chi-Square. $A B D$ : adapter-binding domain; RBD: Ras-binding domain; Pkinase: protein tyrosine kinase domain; TAD: transactivation domain; DBD: DNA-binding domain; Tetramer: tetramerization domain.

for $>50 \%$ of CRC PIK3CA mutations according to COSMIC (34) (Fig. 3A-B, Methods, and Supplementary Table S5). In contrast, 7 out of 13 KRAS mutations identified (54\%) corresponded to oncogenic hotspot mutations in codons 12 or 13 (Fig. 3C). Remarkably, these 7 oncogenic KRAS mutations were all identified in normal colon from individuals with CRC. Overall, $30 \%$ of patients with CRC carried a KRAS hotspot mutation in normal colon compared to none of the patients without CRC (Fig. 3D, Pearson Chi-Square $p=0.003$ ).

Given the tumor suppressor role of TP53, we deep sequenced all its coding exons. We identified a total of 85 coding mutations, which mostly clustered in the DNA binding domain of the protein and coinciding with areas of high density of CRC mutations in COSMIC (Fig. 3E and Supplementary Table S6). This clustering suggests that TP53 mutations in normal colon are not random but follow patterns of selection similar to those operative in CRC. In addition, $17.7 \%$ of TP53 mutations were high impact mutations (indels, nonsense, or splice), which severely affect protein function, and 9.4\% of the substitutions identified corresponded to the top ten most common TP53 substitutions in CRC, which represent $>50 \%$ of all TP53 mutations reported in COSMIC (Methods). In total, more than a quarter of TP53 mutations identified in normal colon (27.1\%) were either high impact mutations or hotspots. These mutations are likely to confer a selective advantage to the cells that carry them and were considered TP53 driver mutations for the purpose of mutation classification in the study. Patients with CRC were more likely to carry TP53 coding mutations in normal colon than patients without cancer (91.3\% vs $66.7 \%$, Pearson Chi-Square $p=0.039$, Fig. 3F) and also more likely to carry TP53 driver mutations (52.2\% vs $25 \%$, Pearson Chi-Square $p=0.05$, Fig. 3F).

To investigate whether normal colon samples carried concurrently more than one cancer driver mutation, we plotted all the mutations identified for each gene in each patient (Fig. 4). In patients without CRC, we only observed one sample with multiple cancer driver mutations ( 2 in TP53 and 1 in PIK3CA). However, in patients with CRC we identified 6 samples with multiple cancer driver mutations, including 4 samples with driver mutations in KRAS and TP53, and 2 samples with multiple driver mutations in TP53. Overall, patients with CRC were more likely to carry one or more cancer driver mutations in normal colon than patients without CRC (Pearson Chi-Square $p=0.025$, Fig. 3G). Thus, mutations in cancer driver genes are common in the normal colon of patients with CRC, not only as isolated events, but also in concurrence with other cancer driver mutations. 
Of note, the MAF of the mutations identified, including driver mutations, was very low $(<0.004$ except for one mutation at 0.01) (Supplementary Fig. S4, Table S5, and Table S6), which makes them unidentifiable by standard sequencing methods (35). CRISPR-DS, however, enables accurate detection of very low frequency mutations, providing an ultra-high resolution view of the landscape of common CRC mutations in normal colon. The higher representation of cancer driver mutations in the normal colon of individuals with CRC indicates an excess of mutant clones in these patients whose detection by ultra-sensitive sequencing could be valuable for CRC risk prediction.

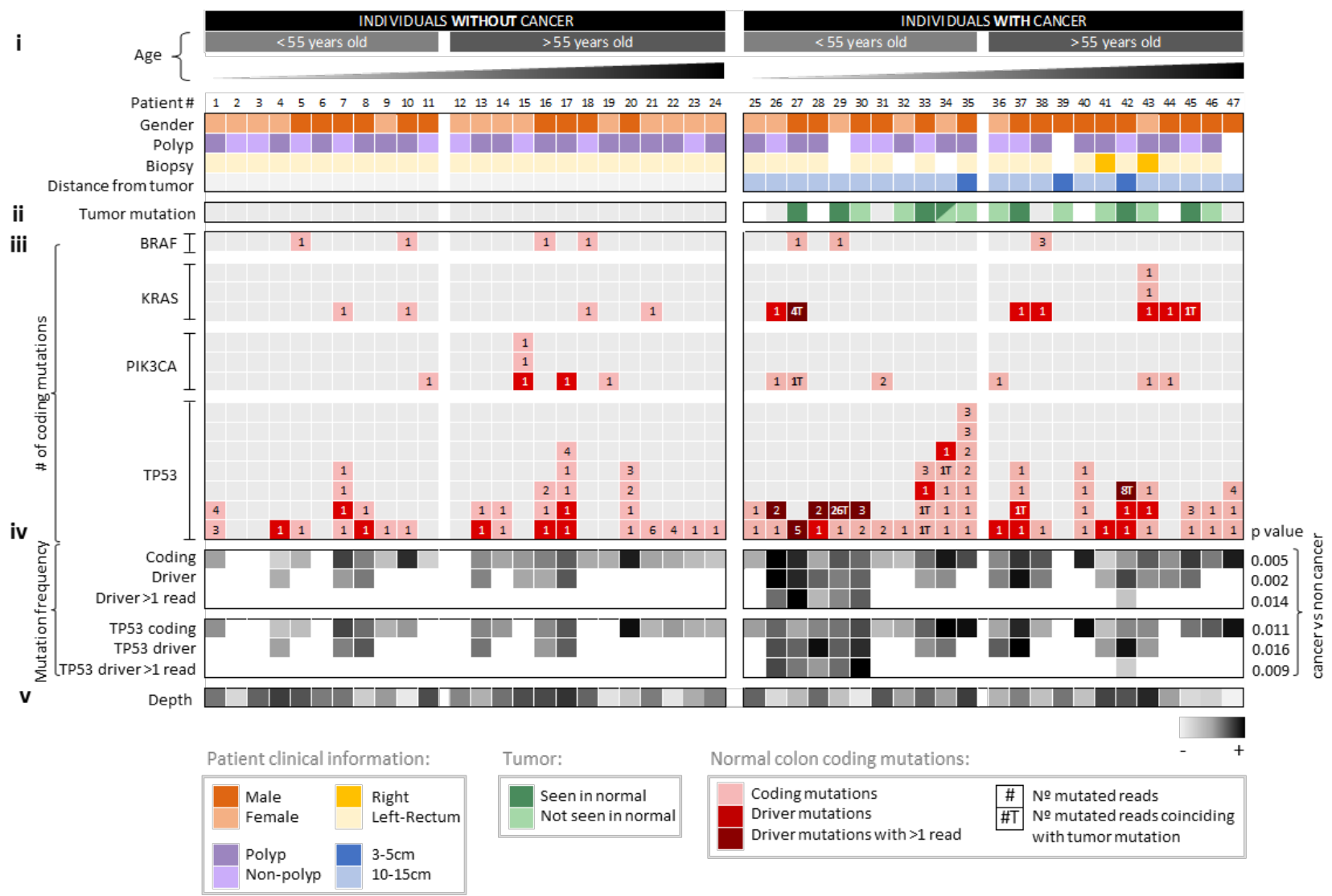

Figure 4. Mutations in normal colon of patients with CRC are often different from mutations in synchronous tumors and, in early onset CRC patients, driver mutations are frequently observed forming large clones. Each column corresponds to a patient. Patients are grouped by cancer status and sorted by ascending age. Panels of data indicate (i) clinical information, (ii) presence of tumor mutation in normal tissue, (iii) normal colon mutation counts for each gene, (iv) normal colon mutation frequency, and (v) depth. In (i) and (ii), white squares indicate that the information is not available and grey squares indicate negative. Tumor mutation was negative for four cases that did not show any mutation in the 4 tested genes. Normal colon mutations for each gene (iii) are indicated with squares that contain the number of mutated reads color coded for mutations that are coding, drivers, and drivers with more than one $(>1)$ mutated duplex read. ' $T$ ' next to the number indicates that the mutation was observed in the synchronous tumor. Driver mutations were conservatively defined as oncogenic hotspots and TP53 hotspots, nonsense, splice, and indel mutations. Greyscale heatmaps (iv) show mutation frequency values based on mutations that are coding, driver, and driver with $>1$ duplex read for all genes and TP53 only. P-values correspond to t-test comparison of the mean frequency between individuals with and without CRC. Depth (v) indicates average duplex depth for all positions sequenced. 
medRxiv preprint doi: https://doi.org/10.1101/2021.10.11.21264780; this version posted October 14, 2021. The copyright holder for this preprint (which was not certified by peer review) is the author/funder, who has granted medRxiv a license to display the preprint in perpetuity. It is made available under a CC-BY-NC-ND 4.0 International license .

\section{Most mutations in normal colon of patients with CRC differ from mutations identified in the cancers of the same patients}

We then investigated whether the mutations observed in the normal colon of individuals with CRC coincided with those detected in the synchronous tumor, indicating possible clonal origin. We sequenced the same 4 gene regions in tumor DNA from 19 patients with available tumor tissue and catalogued all non-synonymous mutations and indel mutations with MAF>0.1 (Supplementary Methods and Supplementary Table S7). In 4 tumors, no such mutations were identified, likely because they were driven by other non-sequenced genes. In 7 out of 15 tumors, at least one non-synonymous TP53, KRAS or PIK3CA mutation was identified in the tumor as well as the normal tissue (Fig. 4 and Supplementary Table S7). However, in all cases, the normal tissue also carried additional cancer gene mutations not detected in the tumor. In addition, in 8 cases, tumor TP53, KRAS and PIK3CA mutations could not be identified in the normal tissue, which nevertheless carried other mutations in these genes. Overall, out of 44 non-synonymous TP53, $K R A S, B R A F$, or PIK3CA mutations identified in the normal colon of 15 individuals with sequenced tumor data, only $9(20.5 \%)$ coincided with a synchronous tumor mutation, indicating that most mutant clones observed in normal colon are not related to the clone that eventually progressed to CRC. These results suggest that multiple independent mutant clones might be abundant in normal colonic mucosa of individuals at risk of CRC, which increases the chance of eventually giving rise to a tumor.

While mutations in individuals without CRC were less abundant, in these patients we identified positive associations between the frequency of TP53 coding mutations and being male ( $t$-test $p=0.056$ ) and carrying polyps (t-test $p=0.054$ ) (Supplementary Fig. S5). Male gender and polyps are two well known risk factors for $\operatorname{CRC}(36,37)$. Smoking and high BMI are also CRC risk factors but were not associated with TP53 mutation in patients without CRC in this study. These results suggest a potential link between TP53 mutations in normal colon and some CRC risk factors.

\section{Clones with cancer driver mutations are larger in patients with early CRC}

Next, we asked whether the mutations identified in the normal colon of individuals with CRC were not only more abundant but also corresponded to larger clones. As duplex depth indicates the number of haploid genomes sequenced, the number of duplex reads containing a given mutation is proportional to the relative size of the clone carrying the mutation. We observed that patients with CRC not only had more driver mutations, but these driver mutations were detected in multiple reads, indicating they were in larger clones (Fig. 4). Large clones were especially common in individuals that developed CRC younger than age 50. The largest clones observed corresponded to mutations also identified in the synchronous tumors, possibly pointing to very large clonal expansions or potentially dissemination of cancer cells more than $10 \mathrm{~cm}$ from the tumor site. Overall, the frequency of coding, driver, and driver in more than one read mutations (for all genes and for TP53 only) was statistically significantly higher in the normal colon of individuals with cancer compared to those without cancer (Fig. 4). However, the differences in mutation frequency between the two groups of patients (cancer and no cancer) were accentuated for younger ( $<55$ yo) individuals (Supplementary Fig. S6). In addition, younger 
medRxiv preprint doi: https://doi.org/10.1101/2021.10.11.21264780; this version posted October 14, 2021. The copyright holder for this preprint (which was not certified by peer review) is the author/funder, who has granted medRxiv a license to display the preprint in perpetuity.

It is made available under a CC-BY-NC-ND 4.0 International license .

individuals with CRC carried a disproportional higher level of large mutant clones compared to older individuals with CRC (Supplementary Fig. S6), suggesting differences in the factors mediating clonal expansion and possibility progression to CRC in young and old individuals.

A
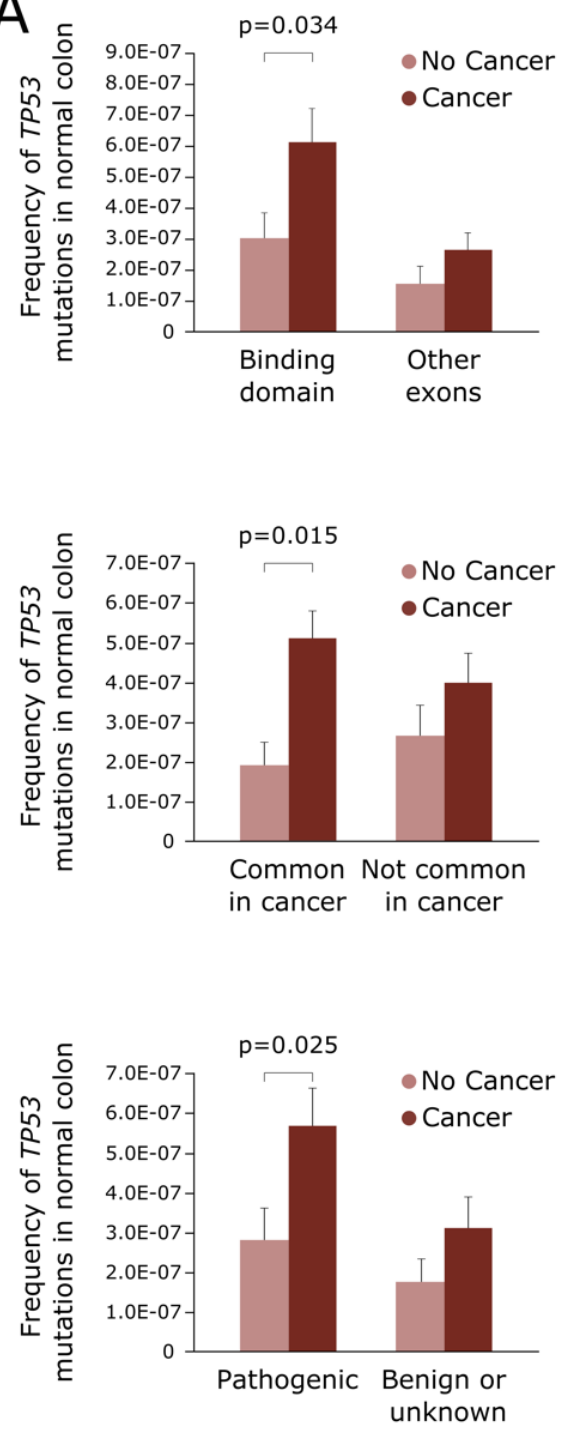

B
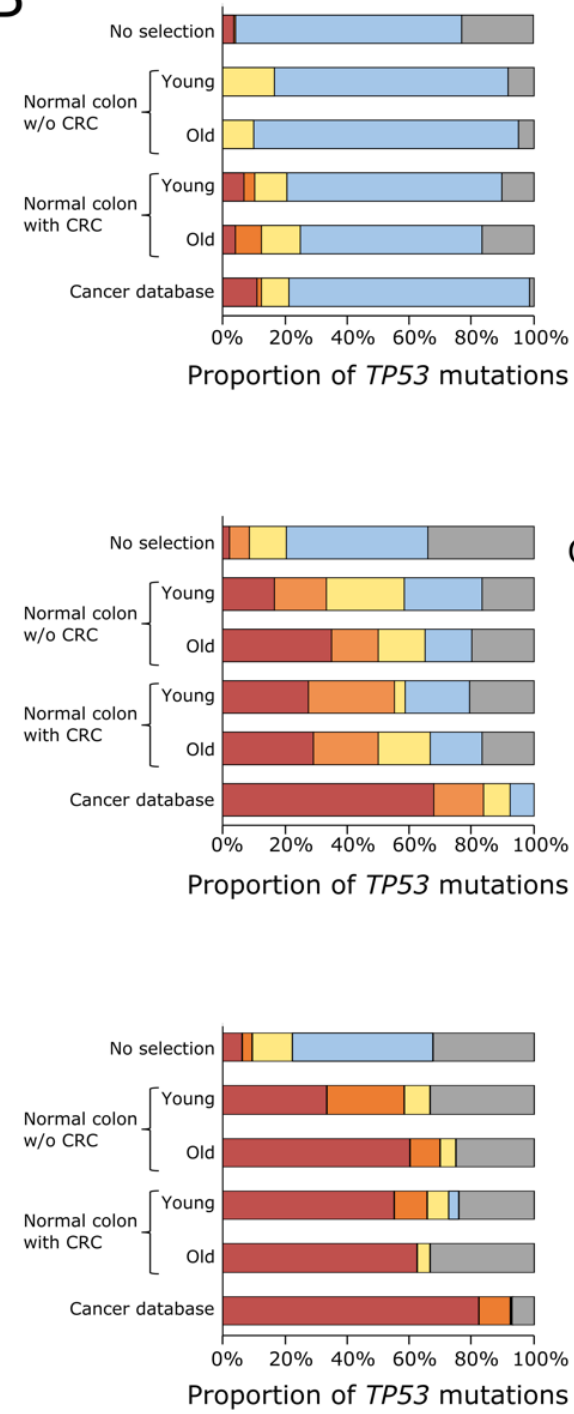

Mutation type

$\square$ Synonymus

$\square$ Missense

$\square$ Indel

$\square$ Splice

Nonsense

\section{Cancer Frequency}

$\square$ Never seen in cancer

$\square$ Rare/unique

$\square$ Not frequent

$\square$ Frequent

$\square$ Very Frequent

Figure 5. TP53 mutations identified in normal colon are more pathogenic in individuals with CRC than individuals cancer-free and more closely resemble TP53 mutations identified in CRC. A. TP53 mutation frequency of individuals with and without CRC was compared based on mutations localized in the binding domain, mutations common in CRC, and mutations predicted to be pathogenic. Data was extracted from Seshat (ref. 38). Only significant p-values of t-tests are displayed. Error bars represent standard error of the mean. B. Distribution of TP53 mutations by mutation type, cancer frequency, and pathogenicity in normal colon of young ( $<55$ years old) and old ( $\geq 55$ years old) individuals without and with CRC compared to all possible TP53 mutations in the coding region (no selection, $\mathrm{n}=$ $3,546)$ and TP53 mutations reported in CRC in the UMD cancer database $(n=17,681)$. Number of TP53 mutations in each group: young without $C R C n=12$; old without $C R C n=20$; young with $C R C n=29$; old with $C R C n=24$. 
medRxiv preprint doi: https://doi.org/10.1101/2021.10.11.21264780; this version posted October 14, 2021. The copyright holder for this preprint (which was not certified by peer review) is the author/funder, who has granted medRxiv a license to display the preprint in perpetuity. It is made available under a CC-BY-NC-ND 4.0 International license .

TP53 mutations in normal colon are more commonly pathogenic in individuals with CRC and more closely resemble mutations reported in CRC

TP53 mutations were further assessed using Seshat, a web service tool that provides functional data specific for TP53 variants, including frequency in the UMD database and predicted pathogenicity (38). We classified the mutations according to their location in the protein DNAbinding domain, their frequency in cancer, and their pathogenicity (See Supplementary Methods). Patients with CRC had a significantly higher mutation frequency of TP53 mutations that are located in the DNA binding domain, are common in cancer, and are predicted to be pathogenic, compared to individuals without CRC (Fig. 5A).

We then investigated the type, frequency, and pathogenicity of TP53 mutations observed in normal colon compared with mutations reported in colon carcinomas in the UMD database (2021, $n=17,681$ ) and with all the possible TP53 coding mutations in the theoretical absence of selection ( $n=3,546)$ (Fig. $5 B$ ). Mutations identified in normal colon samples were predominantly missense, similar to mutations reported in CRC or in TP53 in the absence of selection. However, only the normal colon of patients with CRC carried nonsense and splicing mutations, which are considered highly damaging, in similar proportions to what is observed in the cancer database. The distribution of mutations reported in normal colon that are frequently found in cancers and predicted to be pathogenic clearly differed from the expected pattern of mutations in TP53 under no selection and strongly resembled the pattern observed in the cancer database, especially in older individuals and those with CRC (Fig. 5B). These results suggest that there is a common process of positive selection of TP53 mutant clones that is operative in normal colon as well as in CRC. However, this process appears to be enhanced with aging and in those patients that develop CRC.

Integrative mutational analysis and proof-of-principle studies for the development of a CRC predictor

Our results provide support for the concept of creating a CRC risk predictor based on the normal colonic mucosa mutational profile. An essential step towards that goal is to construct a predictive model summarizing and harmonizing the mutational analysis results. Due to multicollinearity and to avoid overfitting, we used regularized logistic regression with Lasso penalty estimated to determine the 5 variables that were the best predictors (Supplementary Table S8, Methods). All quantitative variables with prior demonstrated significance in univariate analyses were included in the model as well as their interaction with age in order to determine potential differential effects between young and old individuals. The variables with the largest effects were the frequency of driver mutations $(\mathrm{OR}=2.16)$ and the presence of hotspots in KRAS $(\mathrm{OR}=1.86)$. Additional information was gained when considering the frequency of TP53 coding mutations, TP53 mutations common in cancer, and the interaction between drivers mutations with $>1$ supporting read and age (ORs of 1.26, 1.066, and 1.26, respectively). This later interaction indicates that the risk of CRC increases with increased frequency of larger clones (represented by mutations identified in more than 1 read) but only in younger individuals. The predicted accuracy of the model was good, with AUC $=0.6995 \% \mathrm{Cl}$ : 0.53-0.85 after 5-fold cross-validation. While 
medRxiv preprint doi: https://doi.org/10.1101/2021.10.11.21264780; this version posted October 14, 2021. The copyright holder for this preprint (which was not certified by peer review) is the author/funder, who has granted medRxiv a license to display the preprint in perpetuity. It is made available under a CC-BY-NC-ND 4.0 International license .

this preliminary analysis included a small number of cases and requires validation in larger studies, it demonstrates the potential of this approach for the development of a CRC predictor based on the mutational analysis of biopsies collected from histologically normal mucosa.

\section{DISCUSSION}

In this study we used deep sequencing with CRISPR-DS to perform high resolution singlemolecule characterization of common colorectal cancer mutations in normal colon of individuals with and without CRC. We found that patients with CRC carried abundant oncogenic KRAS and TP53 driver mutations in normal colonic epithelium distant from the primary tumor and that these clones were larger in patients with early onset CRC. In addition, most of the mutations identified in normal colon were different from the mutations in cancers, suggesting the presence of multiple, independent mutant clones in association with CRC progression. These results expand our understanding of somatic evolution in the colon, offer insights about different mechanisms of carcinogenesis in early vs late onset CRC, and raise the possibility of using normal colon biopsies for CRC risk assessment.

Prior studies have demonstrated an age associated increase of somatic mutations in normal colon $(14,15,39)$ in agreement with our findings for non-coding mutations. By focusing on cancer driver mutations and leveraging ultra-deep, single-molecule sequencing, our study expands these initial findings and demonstrates that, in addition to the age-related increase of somatic mutations, the normal colon of individuals with CRC frequently carries clones with oncogenic KRAS and pathogenic TP53 mutations. In some cases, we identified the same mutation in the normal biopsy and the tumor, which could be explained by a very large epithelial clonal expansion (at least $10 \mathrm{~cm}$ long) from which the cancer evolved. Large clonal expansions have been previously described in the colon of patients with ulcerative colitis $(40,41)$, who are prone to CRC, and exemplify the concept of carcinogenic fields (also known as field effect or field cancerization) by which the normal cell population is replaced by a cancer-primed cell population that is morphologically normal but carries some of the phenotypes required for malignancy (42). In most cases in our study, the driver mutation identified in normal colon did not coincide with the driver mutation in the tumor, suggesting the presence of fields composed by multiple precancerous clonal expansions as opposed to a single large clonal patch. Supporting this notion, six normal colon biopsies in patients with CRC carried two or more different driver mutations and, in three cases, one of the driver mutations was seen in the tumor, but not the others. While larger studies using multiple normal biopsies per individual are warranted to characterize the extension and composition of precancerous fields in CRC, the data obtained here reveals their high prevalence and demonstrates the feasibility of using single-molecule ultra-deep sequencing for their identification.

Lee-Six et al recently demonstrated that by the sixth decade of life around $1 \%$ of normal colon crypts carry a clonal driver mutation (15). Interestingly, most mutations identified were in genes rarely mutated in CRC, such as ERBB2 and ERBB3, and their frequency in normal colon was similar in patients with and without CRC. The authors suggested that these mutations likely contribute 
medRxiv preprint doi: https://doi.org/10.1101/2021.10.11.21264780; this version posted October 14, 2021. The copyright holder for this preprint (which was not certified by peer review) is the author/funder, who has granted medRxiv a license to display the preprint in perpetuity. It is made available under a CC-BY-NC-ND 4.0 International license .

to crypt colonization by mutant stem cells whereas mutations in TP53 and KRAS might enable subsequent preneoplastic transformation. Our results support this hypothesis by demonstrating that oncogenic KRAS mutations and pathogenic TP53 mutations are infrequent in normal colon of patients without CRC but abundant in individuals that progressed to CRC. The finding of KRAS oncogenic mutations in normal colon of about one third of patients with CRC suggests a link between these mutant clones and the progression to CRC. KRAS mutations have been postulated to enable the lateral expansion of mutant crypts $(43,44)$ providing a plausible mechanism for the generation of large patches of mutant cells from which tumors develop. In addition, phylogenetic reconstruction of CRC evolution has revealed that TP53 and KRAS mutations are very early events, which take place after APC mutations decades prior to the development of CRC (1). Our results expand these findings by revealing that TP53 and KRAS mutations can be identified even in histologically normal epithelium of patients with CRC suggesting that multiple mutant clones accumulate in these individuals through life, one of which eventually evolves into cancer.

In this study, we purposely included individuals with early onset CRC to investigate the nature of clonal expansions in the normal colon when cancer develops at younger age. The incidence of early onset CRC has increased substantially in the last 2 decades for unclear reasons (29). We discovered that almost one half of younger individuals with CRC (5/11) harbor a large clone containing a TP53 driver mutation suggesting that the development of CRC in a large proportion of young individuals might be related to large expansions of TP53 mutant clones in normal colon. Interestingly, early-onset CRC has been reported to have a high prevalence of TP53 mutations and whole genome doubling (45), which suggests, in concordance to our data, that there might be different carcinogenic processes in early onset vs late onset CRC, the former involving frequent TP53 loss in early stages of carcinogenesis.

In patients without CRC, we observed the highest levels of mutations in males and patients with polyps, which are risk factors for CRC. While larger numbers are required to confirm these associations, these findings agree with prior studies of somatic mutations in normal esophagus, in which smoking and alcohol consumption, which are well-known risk factors for esophageal adenocarcinoma, were associated with higher mutation burden (9). Thus, it is possible that the characterization of somatic mutation in normal colon might be useful to investigate the mechanisms of action of CRC epidemiological risk factors in addition to serve as a potential biomarker for cancer risk prediction.

A limitation of our study is that the gene panel was small and therefore, we cannot extract information about mutational signatures, which are helpful to elucidate mutation etiology. The goal of this study, however, was to determine whether ultra-sensitive sequencing of normal colon could have clinical value to assess CRC risk and, towards that goal, smaller panels are preferred to facilitate clinical applicability. In fact, we have demonstrated excellent predictive value by considering only the information provided by KRAS and TP53 indicating that a future biomarker might be successful solely based on those genes. A smaller panel enables to dedicate sequencing resources to achieve higher depth and/or screen more biopsies, providing more accurate estimates of clone size and abundance. This approach is well aligned with recently proposed efforts to develop panels of hotspot cancer driver mutations as biomarkers of cancer 
medRxiv preprint doi: https://doi.org/10.1101/2021.10.11.21264780; this version posted October 14, 2021. The copyright holder for this preprint (which was not certified by peer review) is the author/funder, who has granted medRxiv a license to display the preprint in perpetuity. It is made available under a CC-BY-NC-ND 4.0 International license .

risk using error corrected NGS (46). A second limitation of the study is that normal colon prior to the development of CRC was not tested. Moving forward, that assessment will be critical to demonstrate predictive value. The easy accessibility of the colon and established colonoscopic surveillance make it possible to obtain biopsies prior to CRC progression offering an excellent scenario for cancer risk prediction as well as a unique opportunity to study clonal evolution as a function of aging and exposures.

In summary, we have demonstrated that normal colon from patients with and without CRC carry mutations in common colorectal cancer genes, but these mutations are more abundant in patients with cancer. In addition, individuals with cancer carry more mutations that are canonical cancer drivers, especially in KRAS and TP53, and these mutations tend to be found in larger clones. Our results support the notion that somatic evolution contributes to clonal expansions in the normal colon and that this process is enhanced in individuals with cancer and, most significantly, in those with early onset CRC. These findings open the possibility for the development of a CRC predictor based on ultra-deep analysis of mutations in normal colonic biopsies.

\section{METHODS}

\section{Subjects and samples}

This study included normal colon mucosa samples $(n=47)$ collected at the University of Washington Medical Center and affiliated practice sites (Seattle, WA, USA) from 24 patients without colorectal adenocarcinoma (CRC) undergoing colonoscopic screening or surveillance and from 23 patients with a newly diagnosed primary invasive colorectal adenocarcinoma undergoing surgical resection. Clinico-pathological characteristics of patients are listed in Supplementary Table S1. None of the patients had hereditary cancer syndrome. The groups of patients were matched by age and history of polyp(s) and were enriched with young individuals to explore differences in somatic mutations in early vs late onset CRC. Only one patient had neoadjuvant therapy. All normal samples from individuals with CRC were located 10 to $15 \mathrm{~cm}$ from the tumor except for two samples collected between 3 to $5 \mathrm{~cm}$ from the tumor. Immediately after collection, samples were frozen in liquid nitrogen and stored at -80 으 $\mathrm{Cuntil}$ DNA extraction (Supplementary Methods). In addition, Formalin-Fixed Paraffin-Embedded (FFPE) tumor blocks from patients with CRC were histologically examined with hematoxylin and eosin staining followed by microdissection and DNA extraction in 19 cases with sufficient tumor content. DNA extraction and library preparation from tumor DNA (Supplementary Methods) was performed after all normal tissue was analyzed to avoid any chances of crosscontamination. In all but one case, microsatellite instability (MSI) was determined by mismatch repair defect based on routine clinical immunohistochemistry of proteins MLH1, MSH2, MSH6, and PMS2 in tumor FFPE tissue sections. Two cases were MSI positive (Supplementary Table S1). Patients consented for sample collection and the study was conducted following protocols approved by Institutional Review Board committees at the University of Washington and the Fred Hutchinson Cancer Research Center. DNA from colorectal cancer cell lines HCT116, HT29 and SW480 was used for method validation (Supplementary Methods). 
medRxiv preprint doi: https://doi.org/10.1101/2021.10.11.21264780; this version posted October 14, 2021. The copyright holder for this preprint (which was not certified by peer review) is the author/funder, who has granted medRxiv a license to display the preprint in perpetuity. It is made available under a CC-BY-NC-ND 4.0 International license .

\section{CRISPR guide design}

CRISPR-DS employs CRISPR-Cas9 digestion of target regions followed by size selection of excised fragments as a method for efficient target enrichment prior to library preparation (28) (Fig. 1B). We used Benchling [Biology Software, 2020] (San Francisco, CA) to design guide RNAs (gRNAs) to excise the coding regions of the TP53 gene and the hotspot mutation codons of BRAF, KRAS and PIK3CA genes into fragments of $250-280 \mathrm{bp}$. Then we used the CRISPOR web tool (47) to select the best candidates, which included 24 gRNAs (Supplementary Table S2) that excised the target region into 13 fragments with a total panel size of $3461 \mathrm{bp}$. The panel comprised 1953 coding bp and 1508 non-coding bp from intronic regions flanking the excised exons.

\section{CRISPR-DS}

Genomic DNA from normal colon tissues and CRC cell lines was processed for CRISPR-DS as previously described with minor modifications (28) (Supplementary Methods). Hybridization capture was performed with $120 \mathrm{bp}$ biotinylated $x$ Gen Lockdown probes (Integrated DNA Technology, Coralville, IA, USA) designed to target the selected regions of TP53, BRAF, KRAS and PIK3CA (Supplementary Table S3). Libraries were sequenced using 150 PE reads on a MiSeq Illumina platform on site or HiSeq at Genewiz (South Plainfield, NJ), allocating 2 million reads per sample. Sequencing reads were analyzed as previously described (28) using pipeline v1.1.4 from https://github.com/Kennedy-Lab-UW/Duplex-Seq-Pipeline (Supplementary Methods). Mutant Allele Frequency (MAF) was calculated for each mutation as the number of mutated duplex reads divided by the total duplex depth at the given position.

\section{Calculation of mutation frequency}

For each sample, the overall duplex depth was calculated as the total number of duplex nucleotides sequenced divided by the size of the panel. On average, for each sample we sequenced $8.6 \mathrm{M}$ duplex nucleotides corresponding to a duplex depth of $2,484 \mathrm{x}$ (minimum 1,268x; maximum 4,306x) (Supplementary Table S4). To correct for the variability in sequencing depth across samples (Fig. S2), sample comparisons were made based on mutation frequencies, which were calculated as the number of mutations in a given region (e.g., coding, non-coding, TP53 coding) divided by the total number of duplex nucleotides sequenced in that region. Coding included nucleotides in coding exons plus $2 \mathrm{bp}$ boundary nucleotides to capture splice site mutations, and non-coding included all the remaining nucleotides in the target regions. Similarly, mutation frequencies were calculated for specific types of mutations (e.g., drivers) by dividing the number of mutations in the category of interest by the total number of duplex nucleotides sequenced in the target region. Mutation counts and corresponding mutation frequencies for each sample are indicated in Supplementary Table S4.

\section{Mutational analysis}

Coding mutations were extracted from MAF files (Supplementary Methods) and were further annotated by mutation type (missense, nonsense, splice, indel and synonymous), mutation spectrum $(\mathrm{C}>\mathrm{A}, \mathrm{C}>\mathrm{G}, \mathrm{C}>\mathrm{T}, \mathrm{T}>\mathrm{A}, \mathrm{T}>\mathrm{C}$ and $\mathrm{T}>\mathrm{G})$, localization in $\mathrm{CpG}$ dinucleotides, and driver mutations. Mutations in BRAF, KRAS, and PIK3CA were considered driver mutations if they corresponded to common oncogenic hotspot mutations in these genes according to large 
medRxiv preprint doi: https://doi.org/10.1101/2021.10.11.21264780; this version posted October 14, 2021. The copyright holder for this preprint (which was not certified by peer review) is the author/funder, who has granted medRxiv a license to display the preprint in perpetuity. It is made available under a CC-BY-NC-ND 4.0 International license .

intestine carcinoma data from the COSMIC database (https://cancer.sanger.ac.uk/cosmic) (34). The following oncogenic driver mutations were considered: BRAF V600E, which accounts for $>90 \%$ of BRAF mutations in CRC; KRAS hotspot mutations in codons 12 and 13, which account for $>90 \%$ of KRAS mutations in CRC; and PIK3CA hotspot mutations E545K, H1047R and E542K, which account for $>50 \%$ of PIK3CA mutations in CRC. Driver mutations in TP53 included the 10 most common substitutions according to the COSMIC database, which represent $>50 \%$ of all mutations reported in large intestine carcinomas (p.R175H, p.R273H, p.R248Q, p.R282W, p.R273C, p.R248W, p.G245S, p.R213*, p.R196* and p.R306*), and all splice, indels and nonsense mutations. The list of annotated coding mutations for oncogenes and TP53 are presented in Supplementary Tables S5 and S6, respectively. Large intestine carcinoma variants from COSMIC were also used to determine the mutation spectrum ( 6 possible nucleotide substitutions) of CRC $(n=70,525)$ (Fig. 2E) as well as the distribution of CRC mutations within the protein domains of the genes of interest (Fig. $3 A-C, E$ ).

\section{Statistical analysis}

Correlations were tested with Spearman's rank test. Comparison of mutation frequency means across groups of individuals was performed by t-test. Associations between categorical variables were tested with Pearson Chi-Square. All tests were two-sided at an alpha level (type 1 error rate) of 0.05 . The predictive model was estimated with the glmnet R package (48), with parameters for Lasso logistic regression. The penalization parameter was selected to restrict the model to 5 covariates. Predictive accuracy was calculated with the area under the ROC curve and its $95 \%$ confidence intervals as implemented in the pROC R package (49). Statistical analyses were performed with SPSS version 25 and $R$ version 3.6.3.

\section{Software availability}

Software is available at https://github.com/Kennedy-Lab-UW/Duplex-Seq-Pipeline.

\section{Data access}

Sequencing data from this study have been submitted to the NCBI BioProject database (https://www.ncbi.nlm.nih.gov/bioproject) under accession number PRJNA767868.

\section{Conflict of interest}

RAR is a consultant and equity holder at TwinStrand Biosciences Inc. and an equity holder at NanoString Technologies Inc. RAR is named inventor on patents owned by the University of Washington and licensed to TwinStrand Biosciences Inc. MAP is cofounder and equity holder at Aniling. MAP's laboratory has received research funding from Celgene. VM is equity holder of Aniling.

\section{Acknowledgments}

This work was supported in part by i-PFIs (IFI16/00012) and M-AES (MV19/00042) research fellowships from Instituto de Salud Carlos III to JM; Agencia Estatal de Investigación (RTI2018094009-B-100) to MAP; startup funds from the Department of Laboratory Medicine and 
Pathology to RAR; R50CA233042 to MY; P01CA077852, P30CA042014, P30CA15704, R01189184, R01CA194663, R01CA207371, R01CA220004, U01CA206110, U54CA143862, Listwin Family Foundation, Cottrell Family Fund, R.A.C.E.Charities, Seattle Translational Tumor Research, Rodger C. Haggitt Endowed Chair, and W.H. Geiger Family Foundation to WMG; and Agency for Management of University and Research Grants (AGAUR) of the Catalan Government grant 2017SGR723 to VM. We thank Dr. Scott Kennedy for manuscript revision and members of the Risques and Kennedy Lab at the University of Washington and Grady lab at the Fred Hutchinson Cancer Research Center for technical assistance. We are grateful to the ColoCare and GiCare Studies for providing patient samples and we deeply thank all the patients who donated samples, without which this research would not have been possible.

\section{Author Contributions}

JM, WG, MAP and RAR designed research, selected tissues to be studied, and acquired tissue samples; JM, JF, and KC performed research; JM, BK, TW, VM, and RAR analyzed the data; SG performed pathological analysis; TS provided analytical resources; MY supervised sample selection; JM, WG, MAP and RAR interpreted data; JM and RAR wrote the article.

\section{REFERENCES}

1. Gerstung M, Jolly C, Leshchiner I, Dentro SC, Gonzalez S, Rosebrock D, et al. The evolutionary history of 2,658 cancers. Nature 2020;578:122-8

2. Fittall MW, Van Loo P. Translating insights into tumor evolution to clinical practice: promises and challenges. Genome medicine 2019;11:20

3. Tomasetti C. Mutated clones are the new normal. Science 2019;364:938-9

4. Ellis P, Moore L, Sanders MA, Butler TM, Brunner SF, Lee-Six H, et al. Reliable detection of somatic mutations in solid tissues by laser-capture microdissection and low-input DNA sequencing. Nat Protoc 2021;16:841-71

5. Jager M, Blokzijl F, Sasselli V, Boymans S, Janssen R, Besselink N, et al. Measuring mutation accumulation in single human adult stem cells by whole-genome sequencing of organoid cultures. Nat Protoc 2018;13:59-78

6. Martincorena I, Roshan A, Gerstung M, Ellis P, Van Loo P, McLaren S, et al. Tumor evolution. High burden and pervasive positive selection of somatic mutations in normal human skin. Science 2015;348:880-6

7. Tang J, Fewings E, Chang D, Zeng H, Liu S, Jorapur A, et al. The genomic landscapes of individual melanocytes from human skin. Nature 2020;586:600-5

8. Martincorena I, Fowler JC, Wabik A, Lawson ARJ, Abascal F, Hall MWJ, et al. Somatic mutant clones colonize the human esophagus with age. Science 2018;362:911-7 
medRxiv preprint doi: https://doi.org/10.1101/2021.10.11.21264780; this version posted October 14, 2021. The copyright holder for this preprint (which was not certified by peer review) is the author/funder, who has granted medRxiv a license to display the preprint in perpetuity. It is made available under a CC-BY-NC-ND 4.0 International license .

9. Yokoyama A, Kakiuchi N, Yoshizato T, Nannya Y, Suzuki H, Takeuchi Y, et al. Age-related remodelling of oesophageal epithelia by mutated cancer drivers. Nature 2019;565:312-7

10. Suda K, Nakaoka H, Yoshihara K, Ishiguro T, Tamura R, Mori Y, et al. Clonal Expansion and Diversification of Cancer-Associated Mutations in Endometriosis and Normal Endometrium. Cell Rep 2018;24:1777-89

11. Moore L, Leongamornlert D, Coorens THH, Sanders MA, Ellis P, Dentro SC, et al. The mutational landscape of normal human endometrial epithelium. Nature 2020;580:640-6

12. Lawson ARJ, Abascal F, Coorens THH, Hooks Y, O'Neill L, Latimer C, et al. Extensive heterogeneity in somatic mutation and selection in the human bladder. Science 2020;370:75-82

13. Li R, Du Y, Chen Z, Xu D, Lin T, Jin S, et al. Macroscopic somatic clonal expansion in morphologically normal human urothelium. Science 2020;370:82-9

14. Blokzijl F, de Ligt J, Jager M, Sasselli V, Roerink S, Sasaki N, et al. Tissue-specific mutation accumulation in human adult stem cells during life. Nature 2016;538:260-4

15. Lee-Six H, Olafsson S, Ellis P, Osborne RJ, Sanders MA, Moore L, et al. The landscape of somatic mutation in normal colorectal epithelial cells. Nature 2019;574:532-7

16. Li R, Di L, Li J, Fan W, Liu Y, Guo W, et al. A body map of somatic mutagenesis in morphologically normal human tissues. Nature 2021;597:398-403

17. Moore L, Cagan A, Coorens THH, Neville MDC, Sanghvi R, Sanders MA, et al. The mutational landscape of human somatic and germline cells. Nature 2021;597:381-6

18. Fiala C, Diamandis EP. Mutations in normal tissues-some diagnostic and clinical implications. BMC Med 2020;18:283

19. Kennedy SR, Zhang Y, Risques RA. Cancer-Associated Mutations but No Cancer: Insights into the Early Steps of Carcinogenesis and Implications for Early Cancer Detection. Trends in Cancer 2019;5:531-40

20. Risques RA, Kennedy SR. Aging and the rise of somatic cancer-associated mutations in normal tissues. PLoS Genet 2018;14:e1007108

21. Vijg J, Dong X. Pathogenic Mechanisms of Somatic Mutation and Genome Mosaicism in Aging. Cell 2020;182:12-23

22. Schmitt MW, Kennedy SR, Salk JJ, Fox EJ, Hiatt JB, Loeb LA. Detection of ultra-rare mutations by next-generation sequencing. Proc Natl Acad Sci U S A 2012;109:14508-13

23. Kennedy SR, Schmitt MW, Fox EJ, Kohrn BF, Salk JJ, Ahn EH, et al. Detecting ultralowfrequency mutations by Duplex Sequencing. Nat Protoc 2014;9:2586-606

24. Salk JJ, Loubet-Senear K, Maritschnegg E, Valentine CC, Williams LN, Higgins JE, et al. Ultra-Sensitive TP53 Sequencing for Cancer Detection Reveals Progressive Clonal Selection in Normal Tissue over a Century of Human Lifespan. Cell Rep 2019;28:132-44 e3 
medRxiv preprint doi: https://doi.org/10.1101/2021.10.11.21264780; this version posted October 14, 2021. The copyright holder for this preprint (which was not certified by peer review) is the author/funder, who has granted medRxiv a license to display the preprint in perpetuity. It is made available under a CC-BY-NC-ND 4.0 International license .

25. Krimmel JD, Schmitt MW, Harrell MI, Agnew KJ, Kennedy SR, Emond MJ, et al. Ultradeep sequencing detects ovarian cancer cells in peritoneal fluid and reveals somatic TP53 mutations in noncancerous tissues. Proc Natl Acad Sci U S A 2016;113:6005-10

26. Krimmel-Morrison JD, Ghezelayagh TS, Lian S, Zhang Y, Fredrickson J, Nachmanson D, et al. Characterization of TP53 mutations in Pap test DNA of women with and without serous ovarian carcinoma. Gynecologic oncology 2020;156:407-14

27. Siegel RL, Fedewa SA, Anderson WF, Miller KD, Ma J, Rosenberg PS, et al. Colorectal Cancer Incidence Patterns in the United States, 1974-2013. J Natl Cancer Inst 2017;109

28. Nachmanson D, Lian S, Schmidt EK, Hipp MJ, Baker KT, Zhang Y, et al. Targeted genome fragmentation with CRISPR/Cas9 enables fast and efficient enrichment of small genomic regions and ultra-accurate sequencing with low DNA input (CRISPR-DS). Genome Res 2018;28:1589-99

29. Stoffel EM, Murphy CC. Epidemiology and Mechanisms of the Increasing Incidence of Colon and Rectal Cancers in Young Adults. Gastroenterology 2020;158:341-53

30. Park G, Park JK, Shin SH, Jeon HJ, Kim NKD, Kim YJ, et al. Characterization of background noise in capture-based targeted sequencing data. Genome biology 2017;18:136

31. Mouradov D, Sloggett C, Jorissen RN, Love CG, Li S, Burgess AW, et al. Colorectal Cancer Cell Lines Are Representative Models of the Main Molecular Subtypes of Primary Cancer. Cancer Research 2014;74:3238-47

32. Horvath S, Raj K. DNA methylation-based biomarkers and the epigenetic clock theory of ageing. Nat Rev Genet 2018;19:371-84

33. Wang T, Maden SK, Luebeck GE, Li Cl, Newcomb PA, Ulrich CM, et al. Dysfunctional epigenetic aging of the normal colon and colorectal cancer risk. Clin Epigenetics 2020;12:5

34. Tate JG, Bamford S, Jubb HC, Sondka Z, Beare DM, Bindal N, et al. COSMIC: the Catalogue Of Somatic Mutations In Cancer. Nucleic Acids Res 2019;47:D941-D7

35. Salk JJ, Schmitt MW, Loeb LA. Enhancing the accuracy of next-generation sequencing for detecting rare and subclonal mutations. Nat Rev Genet 2018;19:269-85

36. Click B, Pinsky PF, Hickey T, Doroudi M, Schoen RE. Association of Colonoscopy Adenoma Findings With Long-term Colorectal Cancer Incidence. JAMA 2018;319:202131

37. Siegel RL, Miller KD, Goding Sauer A, Fedewa SA, Butterly LF, Anderson JC, et al. Colorectal cancer statistics, 2020. CA Cancer J Clin 2020;70:145-64

38. Tikkanen T, Leroy B, Fournier JL, Risques RA, Malcikova J, Soussi T. Seshat: A Web service for accurate annotation, validation, and analysis of TP53 variants generated by conventional and next-generation sequencing. Human mutation 2018;39:925-33

39. Abascal F, Harvey LMR, Mitchell E, Lawson ARJ, Lensing SV, Ellis P, et al. Somatic mutation landscapes at single-molecule resolution. Nature 2021;593:405-10 
40. Baker KT, Salk JJ, Brentnall TA, Risques RA. Precancer in ulcerative colitis: the role of the field effect and its clinical implications. Carcinogenesis 2018;39:11-20

41. Choi CR, Bakir IA, Hart AL, Graham TA. Clonal evolution of colorectal cancer in IBD. Nat Rev Gastroenterol Hepatol 2017;14:218-29

42. Curtius K, Wright NA, Graham TA. An evolutionary perspective on field cancerization. Nat Rev Cancer 2018;18:19-32

43. Nicholson AM, Olpe C, Hoyle A, Thorsen AS, Rus T, Colombe M, et al. Fixation and Spread of Somatic Mutations in Adult Human Colonic Epithelium. Cell stem cell 2018;22:909-18 e8

44. Olpe C, Khamis D, Chukanova M, Skoufou-Papoutsaki N, Kemp R, Marks K, et al. A Diffusion-like Process Accommodates New Crypts During Clonal Expansion in Human Colonic Epithelium. Gastroenterology 2021;161:548-59 e23

45. Kim JE, Choi J, Sung CO, Hong YS, Kim SY, Lee H, et al. High prevalence of TP53 loss and whole-genome doubling in early-onset colorectal cancer. Exp Mol Med 2021;53:446-56

46. Harris KL, Myers MB, McKim KL, Elespuru RK, Parsons BL. Rationale and Roadmap for Developing Panels of Hotspot Cancer Driver Gene Mutations as Biomarkers of Cancer Risk. Environ Mol Mutagen 2020;61:152-75

47. Concordet JP, Haeussler M. CRISPOR: intuitive guide selection for CRISPR/Cas9 genome editing experiments and screens. Nucleic Acids Res 2018;46:W242-W5

48. Friedman J, Hastie T, Tibshirani R. Regularization Paths for Generalized Linear Models via Coordinate Descent. J Stat Softw 2010;33:1-22

49. Robin X, Turck N, Hainard A, Tiberti N, Lisacek F, Sanchez JC, et al. pROC: an open-source package for $\mathrm{R}$ and $\mathrm{S}+$ to analyze and compare ROC curves. BMC bioinformatics

2011;12:77 
medRxiv preprint doi: https://doi.org/10.1101/2021.10.11.21264780; this version posted October 14, 2021. The copyright holder for this preprint (which was not certified by peer review) is the author/funder, who has granted medRxiv a license to display the preprint in perpetuity. It is made available under a CC-BY-NC-ND 4.0 International license .

\section{SUPPLEMENTARY METHODS}

\section{DNA extraction}

Genomic DNA was extracted from frozen normal colon tissue samples using the DNeasy Blood \& Tissue Kit (Qiagen, Hilden, Germany) and from the FFPE tumor samples using the QIAamp DNA FFPE Tissue Kit (Qiagen). Forceps mucosal biopsies procured at endoscopy were approximately $6 \mathrm{~mm} \times 4 \mathrm{~mm} \times 3 \mathrm{~mm}$ in size and the whole biopsy was used for DNA extraction. In normal colon samples from surgical resections, mucosal epithelium was selected to match the size of the endoscopic biopsies. DNA was quantified by Quant-iT PicoGreen dsDNA Assay Kit (Life Technologies). Cell line DNA was extracted using PureLink ${ }^{\mathrm{TM}}$ Genomic DNA Mini Kit (Invitrogen, Waltham, MA) and DNA was quantified by Qubit dsDNA BR Assay Kit (ThermoFisher Scientific, Waltham, MA). For cell lines and a subset of normal colon samples, DNA quality was assessed with Genomic TapeStation (Agilent Technologies, Santa Clara, CA) and demonstrated high quality in all samples (DNA integrity number (DIN) $\geq 7$ ).

\section{CRISPR-DS library preparation}

CRISPR-DS was performed according to our published protocol (1). Briefly, 100ng of DNA were digested with gRNA-Cas9 complex followed by double size selection with AMPure XP Beads (Beckman Coulter, Brea, CA, USA) to enrich for $260 \mathrm{bp}$ on-target fragments and remove uncut genomic DNA. Then, DNA fragments were end-repaired, A-tailed and ligated with duplex adapters containing $8 \mathrm{bp}$ random double-stranded molecular tags (TwinStrand Biosciences, Seattle, WA, USA) using the NEBNext Ultra II DNA Library Prep Kit (NEB, Ipswich, MA, USA). Ligated DNA was amplified using the KAPA Real-Time Amplification kit with fluorescent standards (KAPA Biosystems, Woburn, MA, USA). Upon purification, regions of interest were captured by hybridization with $120 \mathrm{bp}$ biotinylated XGen Lockdown probes designed to capture previously excised regions of the genes of interest (Integrated DNA Technology, Coralville, IA, USA) (Table S3). A post-capture PCR using indexed primers was performed with KAPA HiFi HotStart PCR kit (KAPA Biosystems, Woburn, MA, USA). Libraries were visualized on the Agilent 4200 TapeStation to confirm the expected peak size. If peaks were not present, a second round of hybridization capture was performed. Libraries were quantified using the Qubit dsDNA HS Assay kit, diluted, and pooled for sequencing.

\section{CRISPR-DS data analysis}

CRISPR-DS sequencing data was analyzed as previously described (1) using pipeline v1.1.4 available at https://github.com/Kennedy-Lab-UW/Duplex-Seq-Pipeline. First, raw reads were grouped using the double stranded molecular tag included in the duplex adapters and a SingleStrand Consensus Sequence read was built from reads sharing the same tag. Then Single-Strand Consensus Sequence reads with complementary tags were compared to produce a single, highly accurate duplex read (Fig. 1B). Duplex reads were aligned to the human genome reference hg38 (GRCH38), end-trimmed, locally realigned, and overlap-trimmed. Variants were called using a 
medRxiv preprint doi: https://doi.org/10.1101/2021.10.11.21264780; this version posted October 14, 2021. The copyright holder for this preprint (which was not certified by peer review) is the author/funder, who has granted medRxiv a license to display the preprint in perpetuity. It is made available under a CC-BY-NC-ND 4.0 International license .

samtools mpileup-based variant caller and output VCF files were converted to MAF files using the Vcf2Maf script (https://github.com/mskcc/vcf2maf) with VEP version 99. All variants identified in SNP positions were discarded for subsequent analysis. Three samples with potential cross-contamination based on SNP frequency were removed from the study. For each mutation, Mutant Allele Frequency (MAF) was calculated as the number of mutated duplex reads divided by the total duplex depth at the given position.

\section{CRISPR-DS validation using CRC cell lines}

CRISPR-DS reproducibility, sensitivity, and efficiency were evaluated using DNA extracted from three common human colorectal cancer cell lines obtained from ATCC (HCT116, HT29 and SW480). One hundred (100) ng of DNA from each cell line was processed for CRISPR-DS in two independent replicate libraries to test reproducibility. To test sensitivity, HT29 DNA was spiked in HCT116 DNA at three different ratios (1:10, 1:20 and 1:100). Library preparation and data analysis were performed using the same methods employed for tissue samples. As each duplex read corresponds to an original DNA molecule, duplex depth indicates the number of haploid genomes analyzed in each position. Thus, the efficiency (also called recovery rate) was calculated as the average duplex depth divided by the number of input genomes corresponding to 100ng of DNA. Driver mutations in each cell line (HCT116: KRAS G13A and PIK3CA H1047A; SW480: KRAS G12V, TP53 R273H and P309S; HT29: BRAF V600E and TP53 R273H; based on https://web.expasy.org/cellosaurus/) were identified in all replicates and with high sensitivity in the spike-in experiment, validating the assay (Supplementary Fig. S1).

\section{Tumor Sequencing}

50-100ng of tumor FFPE DNA were sonicated, end repaired, A-tailed and ligated to duplex adapters using commercial kits (TwinStrand Biosciences, Seattle, WA). Hybridization capture was performed with the same probe pool used for CRISPR-DS of normal colon but using two rounds of hybridization capture as previously recommended (2) (Supplementary Table S3). Enriched libraries were amplified, quantified using the Qubit dsDNA HS Assay kit, diluted, and pooled for sequencing on a MiSeq Illumina platform on site allocating 0.8 million reads per sample. Raw reads were processed with the DS pipeline v2.1.2 available at https://github.com/Kennedy-LabUW/Duplex-Seq-Pipeline. Data analysis was performed on Single-Strand Consensus Sequence (SSCS) reads instead of duplex reads to provide higher depth (mean 284x) and because the goal was to identify tumor driver mutations, which are expected to be clonal and harbor large MAF. For each tumor, we catalogued BRAF, KRAS, PIK3CA, and TP53 non-synonymous or indel mutations with MAF>0.1 and determined whether these mutations coincided with mutations identified in normal colon from the same individual.

\section{TP53 mutation characterization with Seshat}

TP53 mutations were characterized using the Seshat web service tool (https://p53.fr/TP53database/seshat) (3). A MAF file containing all the TP53 mutations observed $(n=118)$ was 
medRxiv preprint doi: https://doi.org/10.1101/2021.10.11.21264780; this version posted October 14, 2021. The copyright holder for this preprint (which was not certified by peer review) is the author/funder, who has granted medRxiv a license to display the preprint in perpetuity. It is made available under a CC-BY-NC-ND 4.0 International license .

submitted to Seshat to accurately annotate, validate, and analyze TP53 variants using data derived from the UMD TP53 database (4). From the Seshat output, coding and splice mutations were extracted $(n=85)$ (Table S6) along with the information about their frequency in the UMD cancer database and predicted pathogenicity. Frequency in the cancer database was categorized as "Common in cancer" (including very frequent and frequent mutations) and "Not common in cancer" (including not frequent, rare, unique, and not seen before mutations). Predicted pathogenicity was categorized as "Pathogenic" (including pathogenic and likely pathogenic mutations) and "Benign or unknown" (including likely benign, benign and variants of unknown significance). In addition, the distribution of TP53 mutations in normal colon based on mutation type, cancer frequency, and pathogenicity was compared to the expected distribution for random TP53 mutations as well as CRC TP53 mutations based on the UMD database (Supplementary Methods).

\section{TP53 mutations without selection}

To compare TP53 mutations in normal colon with the theoretical make up of mutations if they were to occur completely at random and without selection, we generated a list of all possible mutations in the TP53 coding region $(n=3,546)$ and submitted it to Seshat to determine their frequency in cancer and predicted pathogenicity.

\section{UMD TP53 cancer database mutational analysis}

To compare TP53 mutations observed in normal colon with the mutations present in CRC, we used the most recent UMD TP53 cancer database (2021) kindly provided by Dr. Thierry Soussi (Sorbonne Université, Paris, France). We selected all mutations corresponding to colorectal carcinoma samples $(n=17,681)$ and determined the distribution of mutations according to mutation type, frequency in CRC, and predicted pathogenicity. The distribution of TP53 CRC mutations across these variables was compared with the distribution of normal colon mutations for the same variables, divided by patients younger and older than 55 years old and patients with and without CRC.

\section{Bi-Sulfite Conversion and methylation assessment}

DNA (500 ng) from each sample was bisulfite converted using the EZ DNA Methylation Kit (Zymo Research, Irvine, USA). The DNA samples were submitted to the Genomics Core at the Fred Hutchinson Cancer Research Center where they were processed and run on MethylationEPIC arrays following the manufacturer's instructions (Illumina, Inc., San Diego, CA). As previously described, the raw intensity files (IDAT) were preprocessed, normalized, and the array results assessed using four epigenetic age clocks (Hannum, Horvath, PhenoAge and EpiTOC (5)). 


\section{REFERENCES}

1. Nachmanson D, Lian S, Schmidt EK, Hipp MJ, Baker KT, Zhang Y, et al. Targeted genome fragmentation with CRISPR/Cas9 enables fast and efficient enrichment of small genomic regions and ultra-accurate sequencing with low DNA input (CRISPR-DS). Genome Res

2018;28:1589-99

2. $\quad$ Schmitt MW, Fox EJ, Prindle MJ, Reid-Bayliss KS, True LD, Radich JP, et al. Sequencing small genomic targets with high efficiency and extreme accuracy. Nature methods 2015;12:423-5

3. Tikkanen T, Leroy B, Fournier JL, Risques RA, Malcikova J, Soussi T. Seshat: A Web service for accurate annotation, validation, and analysis of TP53 variants generated by conventional and next-generation sequencing. Human mutation 2018;39:925-33

4. Leroy B, Ballinger ML, Baran-Marszak F, Bond GL, Braithwaite A, Concin N, et al. Recommended Guidelines for Validation, Quality Control, and Reporting of TP53 Variants in Clinical Practice. Cancer Res 2017;77:1250-60

5. Wang T, Maden SK, Luebeck GE, Li Cl, Newcomb PA, Ulrich CM, et al. Dysfunctional epigenetic aging of the normal colon and colorectal cancer risk. Clin Epigenetics 2020;12:5 


\section{SUPPLEMENTARY FIGURES}

\section{A}
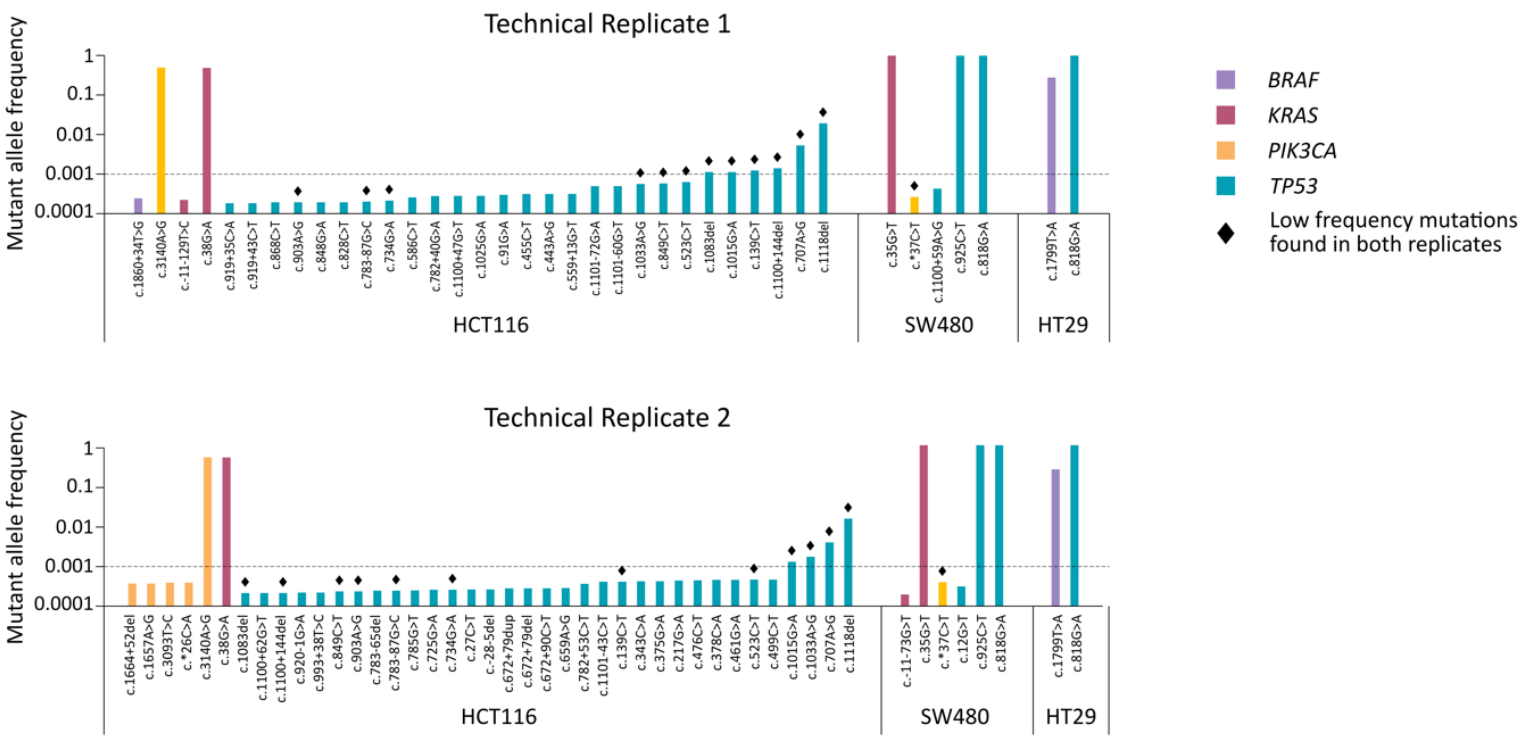

B

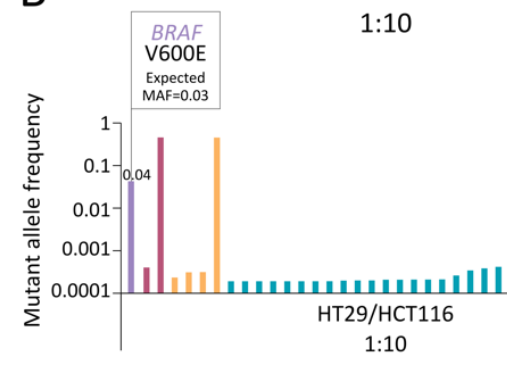

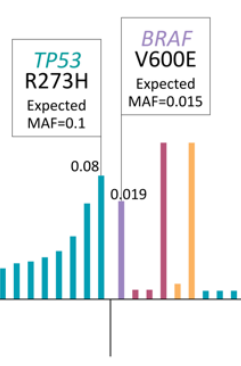

1:20

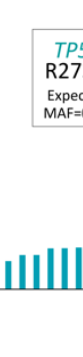

$1: 100$

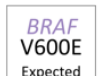

V600E

\begin{tabular}{c} 
Expected \\
MAF $=0.003$ \\
\hline
\end{tabular}

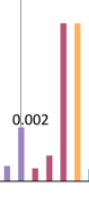
TP53
R273H Expected
MAF $=0.01$

Figure S1. Ultra-deep sequencing of colorectal cancer cell lines with CRISPR-DS. A. Distribution of mutations in two technical replicates of HCT116, SW480 and HT29 cell lines. Each bar represents a mutation, color coded by gene. The height of the bars indicates Mutant Allele Frequency (MAF), calculated as the number of mutant alleles divided by the sequencing depth at a given position. Mutations are sorted by ascending MAF within each gene for each sample. Mutations found in both replicates are highlighted with a black diamond. B. Spike in of HT29 in HCT116 at different concentrations: 1/10,1/20 and 1/100. Expected HT29 mutations and their MAF for each dilution are indicated with boxes and the observed frequency is indicated above each of the corresponding bars. 
medRxiv preprint doi: https://doi.org/10.1101/2021.10.11.21264780; this version posted October 14,2021 . The copyright holder for this preprint (which was not certified by peer review) is the author/funder, who has granted medRxiv a license to display the preprint in perpetuity.

\section{It is made available under a CC-BY-NC-ND 4.0 International license.}

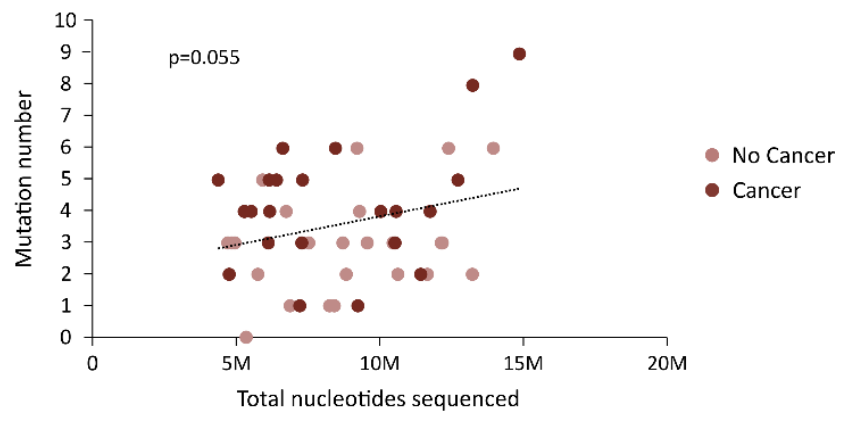

Figure S2. Number of mutations tends to increase with number of total nucleotides sequenced. Correlation between the number of mutations and the total nucleotides sequenced by patient. P-value corresponds to Pearson correlation. 
medRxiv preprint doi: https://doi.org/10.1101/2021.10.11.21264780; this version posted October 14, 2021. The copyright holder for this preprint (which was not certified by peer review) is the author/funder, who has granted medRxiv a license to display the preprint in perpetuity. It is made available under a CC-BY-NC-ND 4.0 International license.

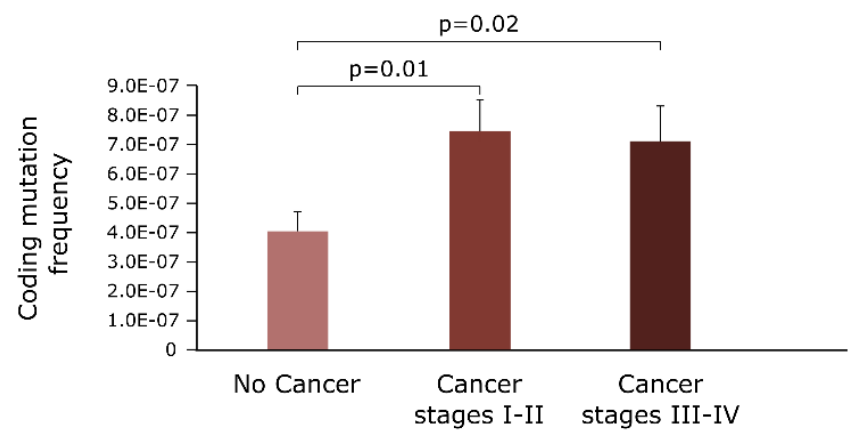

Figure S3. Normal colon from individuals with CRC carries higher coding mutation frequency than individuals without cancer regardless of the cancer being early or late stage. Coding mutation frequency is calculated as the number of mutations divided by the total number of duplex nucleotides sequenced in the coding target regions. Pvalue corresponds to t-test. Error bars represent standard error of the mean. 
A Normal colon of individuals without cancer

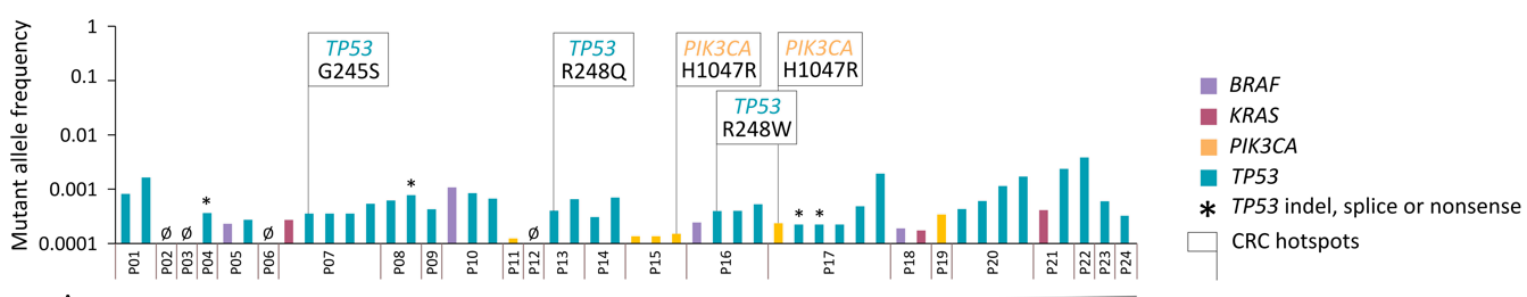
Age

B Normal colon of individuals with cancer

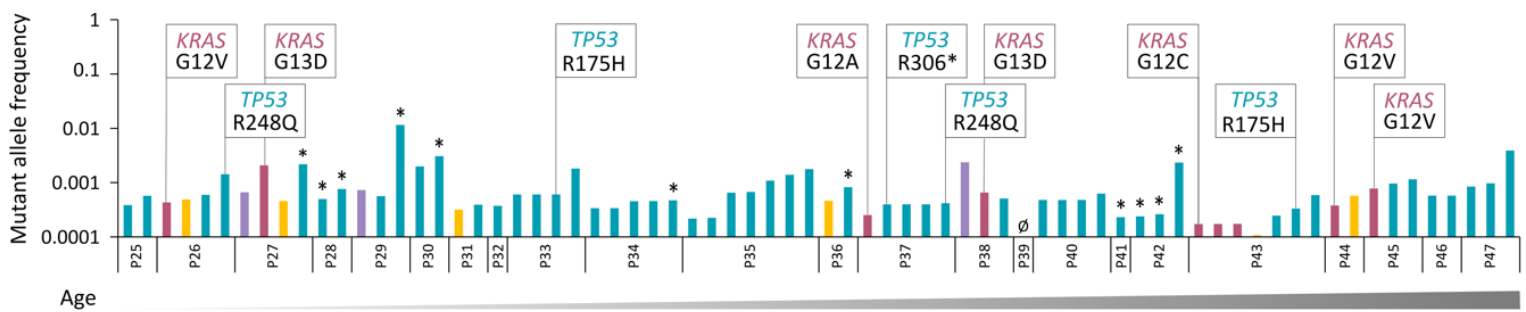

Figure S4. Normal colon from individuals with and without CRC carries mutations in common cancer genes. Distribution of mutations in normal colon from individuals without CRC (A) and individuals with CRC (B). Patients are sorted by ascending age and patient IDs are indicated in the x-axis. Each bar represents a mutation, color coded by gene. The height of the bars indicates Mutant Allele Frequency (MAF), calculated as the number of mutant alleles divided by the sequencing depth at a given position. Mutations are sorted by ascending MAF within each gene for each patient. Hotspot mutations are indicated with boxes and TP53 indels, nonsense, and splice mutations are indicated with asterisks. 
A

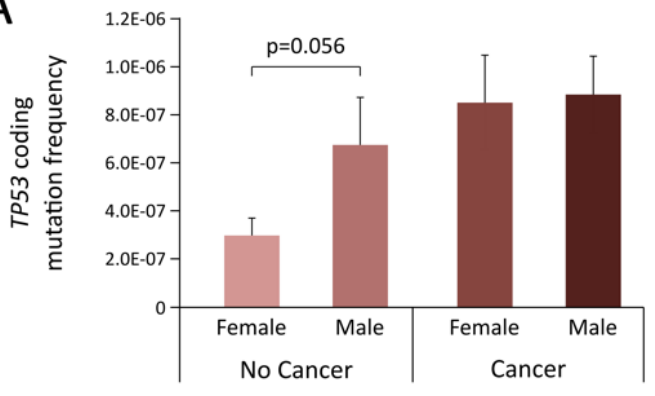

B

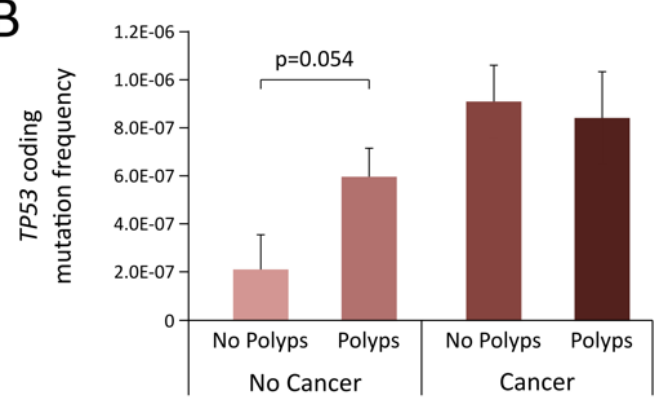

Figure S5. TP53 coding mutations are more frequent in normal colon from individuals without CRC that are males or harbor polyps. Comparison of TP53 mutation frequency in the normal colon of (A) females and males with and without CRC and (B) polyp and non-polyp formers with and without CRC. P-values correspond to t-test comparisons. Error bars represent standard error of the mean. 
medRxiv preprint doi: https://doi.org/10.1101/2021.10.11.21264780; this version posted October 14, 2021. The copyright holder for this preprint (which was not certified by peer review) is the author/funder, who has granted medRxiv a license to display the preprint in perpetuity.

It is made available under a CC-BY-NC-ND 4.0 International license .

A

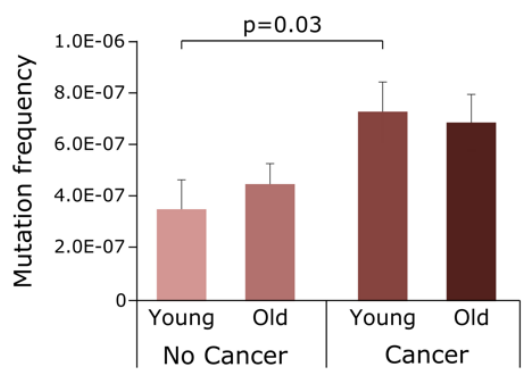

B

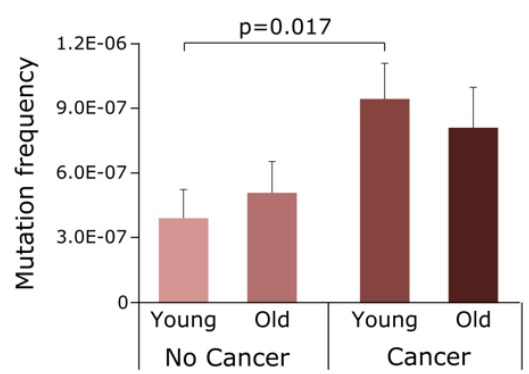

Driver mutations

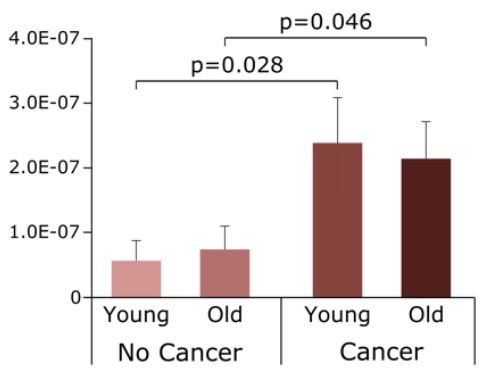

TP53 driver mutations

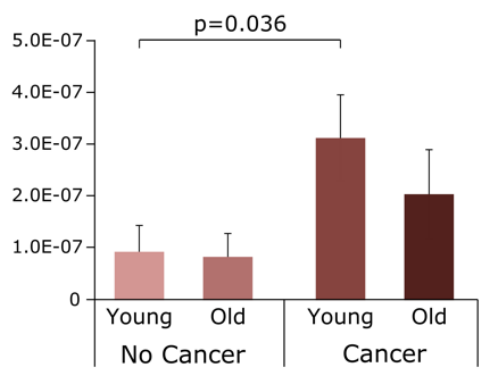

Driver mutations $>1$ read

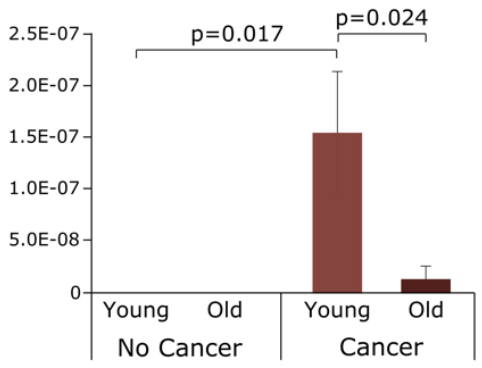

TP53 driver mutations $>1$ read

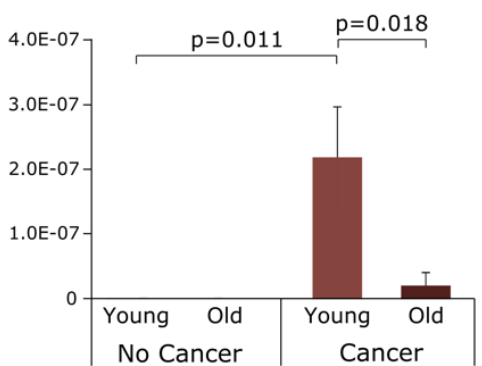

Figure S6. Driver mutations and larger clones are more abundant in the normal colon of young patients with CRC. Comparison of mutation frequency in the normal colon of younger ( $<55$ year old) and older ( $\geq 55$ year old) individuals with and without CRC. Mutation frequencies were calculated for overall (A) and TP53-only (B) mutations that are coding, drivers, and drivers with $>1$ mutated duplex read. P-values correspond to t-test comparisons. Error bars represent standard error of the mean. 